Connel, R.W y Messerschmidt, James, W (2021). Traducción de Barbero, Matías de Stéfano y Morcillo, Santiago. Masculinidad hegemónica. Repensando el concepto. Revista del Laboratorio Iberoamericano para el Estudio Sociohistórico de las Sexualidades, 6, pp-pp. https://doi.org/10.46661/ relies.6364

\title{
Masculinidad hegemónica. Repensando el concepto
}

\author{
Hegemonic Masculinity: Rethinking the Concept ${ }^{1}$
}

\author{
R.W. Connell \\ Universidad de Sydney \\ raewyn.connell@gmail.com \\ https://orcid.org/0000-0001-8001-2375 \\ James W. Messerschmidt \\ Universidad del Sur de Maine \\ mschmidt@maine.edu \\ https://orcid.org/0000-0003-4097-7759 \\ Traducción y comentarios \\ Matías de Stéfano Barbero \\ UBA-CONICET \\ matiasdestefano@hotmail.com \\ https://orcid.org/0000-0001-7561-4267 \\ Santiago Morcillo \\ UBA-CONICET-UNSJ \\ santiagomorcillo@gmail.com \\ https://orcid.org/0000-0001-5809-8635
}

${ }^{1}$ Publicado originalmente en Gender and Society, Vol. 19, No. 6 (Dec., 2005), pp. 829-859. 


\section{Resumen}

El concepto de masculinidad hegemónica ha influenciado los estudios de género en varios campos académicos, pero también ha generado serias críticas. Les autores rastrean el origen del concepto en una convergencia de ideas de principios de la década de 1980, y mapean su aplicación cuando se expandió la investigación sobre hombres y masculinidades. Al evaluar las principales críticas, les autores defienden el concepto subyacente de masculinidad, que en la mayoría de las investigaciones no se utiliza de forma reificante ni esencialista. Sin embargo, las críticas sobre los modelos de rasgos de género y las tipologías rígidas han tenido mucho eco. El abordaje del tema en la investigación sobre masculinidad hegemónica puede ser mejorado con la ayuda de recientes modelos psicológicos, aunque deben reconocerse límites a la flexibilidad discursiva. El concepto de masculinidad hegemónica no equivale a un modelo de reproducción social; se debe reconocer los conflictos sociales en los que las masculinidades subordinadas influencian a las formas dominantes. Finalmente, les autores revisan lo que ha sido confirmado desde las primeras formulaciones (la idea de múltiples masculinidades, el concepto de hegemonía, y el énfasis en el cambio) y lo que debe ser descartado (el tratamiento unidimensional de la jerarquía y el modelo de rasgos de género). Les autores sugieren reformular el concepto en cuatro dimensiones: complejizar el modelo de jerarquía de género, enfatizando la agencia de las mujeres; reconocer explícitamente la geografía de las masculinidades, enfatizando la interrelación entre los niveles locales, regionales y globales; un tratamiento más específico de la encarnación en contextos de privilegio y poder; y un mayor énfasis en las dinámicas de la masculinidad hegemónica, reconociendo las contradicciones internas y los posibles avances hacia la democracia de género.

Palabras clave: masculinidad; hegemonía; género; poder; agencia; encarnación; globalización.

\section{Abstract}

The concept of hegemonic masculinity has influenced gender studies across many academic fields but has also attracted serious criticism. The authors trace the origin of the concept in a convergence of ideas in the early 1980s and map the ways it was applied when research on men and masculinities expanded. Evaluating the principal criticisms, the authors defend the underlying concept of masculinity, which in most research use is neither reified nor essentialist. However, the criticism of trait models of gender and rigid typologies is sound. The treatment of the subject in research on hegemonic masculinity can be improved with the aid of recent psychological models, although limits to discursive flexibility must be recognized. The concept of hegemonic masculinity does not equate to a model of social reproduction; we need to recognize social struggles in which subordinated masculinities influence dominant forms. Finally, the authors review what has been confirmed from early formulations (the idea of multiple masculinities, the concept of hegemony, and the emphasis on change) and what needs to be discarded (one dimensional treatment of hierarchy and trait conceptions of gender). The authors suggest reformulation of the concept in four areas: a more complex model of gender hierarchy, emphasizing the agency of women; explicit recognition of the geography of masculinities, emphasizing the interplay among local, regional, and global levels; a more specific treatment of embodiment in contexts of privilege and power; and a stronger emphasis on the dynamics of hegemonic masculinity, recognizing internal contradictions and the possibilities of movement toward gender democracy.

Keywords: masculinity, hegemony, gender, social power, agency, embodiment, globalization. 
Connel, R.W y Messerschmidt, James, W (2021). Traducción de Barbero, Matías de Stéfano y Morcillo, Santiago. Masculinidad hegemónica. Repensando el concepto. Revista del Laboratorio Iberoamericano para el Estudio Sociohistórico de las Sexualidades, 6, pp-pp. https://doi.org/10.46661/ relies.6364

\section{1 ¿Ya no es lo que era? Introducción a la traducción de "Masculinidad hegemónica. Repensando el concepto"}

Si "masculinidad hegemónica" es leída e invocada para reemplazar al "machismo"; si ha devenido en una forma de nombrar a un varón blanco, cis, heterosexual, proveedor, racional, independiente, valiente, arriesgado, autoritario y potencialmente agresivo; si cuando alguien nos habla de masculinidad hegemónica podemos ya presuponer todo lo que nos está diciendo sin importar el contexto histórico y geopolítico, ni ninguna otra de las coordenadas que nos permitiría situarla, ¿ies entonces momento de declarar la muerte por reificación del concepto de masculinidad hegemónica como herramienta analítica de las ciencias sociales?

En las últimas décadas, muchos de los conceptos vinculados a las ciencias sociales y los estudios de género han ido ganando alcance y se han instalado en nuestro repertorio cotidiano, pasando a formar parte del sentido común con el que pensamos la realidad social. Conceptos como género, masculinidad o patriarcado, se encuentran hoy presentes en los discursos expertos y legos, en los ámbitos académicos y activistas, en políticas públicas y en los medios de comunicación. Pero el alcance que han ganado estos conceptos los ha vuelto escurridizos, polisémicos o directamente equívocos y, como este texto muestra, ha hecho que sean constantemente debatidos y revisados.

Cuando Connell y Messerschmidt sondearon la circulación del concepto en 2005 encontraron algunos centenares de artículos que lo mencionaban. Hoy, una búsqueda en Google Scholar arroja alrededor de diez mil referencias al concepto en artículos científicos escritos en castellano. Por aquel entonces, uno de los problemas que señalaron les autores fue que, junto con la gran circulación que tuvo, sobrevino una fuerte reificación del concepto. Varios años después, en el auge de un nuevo crecimiento de los feminismos a nivel global y en ámbito hispanoamericano, la idea de "masculinidad hegemónica" es casi parte del acervo de sentido común, al menos en las clases medias. Sin embargo, en numerosas ocasiones (acaso la mayoría), la masculinidad hegemónica funciona como un sinónimo modernizado del antiguo "machismo". La idea de un conjunto de relaciones complejas, dinámicas y marcadas por sus contextos culturales e históricos, se desvanece frente al estereotipo como referencia más rápida y accesible.

Tal como Connell y Messerschmidt plantean el concepto, el conjunto de relaciones complejas al que alude la masculinidad hegemónica surge del análisis de la intersección de diferentes vectores de opresión, donde no sólo interviene él género, sino también la sexualidad, la clase, la raza, las edades, entre otros. Este análisis fue el que permitió la pluralización del concepto de masculinidad. Sin embargo, aquí también emerge otro problema en tanto la pluralización puede conducir a la construcción de un abanico de tipologías de masculinidad, no solo hegemónica, subordinada, cómplice o marginal, sino también la masculinidad negra, gaucha, u obrera. Así, el concepto "masculinidades", aunque se torna más simple, también pierde su filo crítico y se torna puramente 
descriptivo: decimos "masculinidades" porque hay varias formas de ser hombre, y las relaciones de poder quedan eclipsadas.

Si bien la descripción es una de las funciones de los conceptos que acuñamos en ciencias sociales, resulta fundamental tanto mantener el dinamismo y la situacionalidad de esas descripciones, como no olvidar otras funciones que cumplen los conceptos. A menudo utilizamos el concepto "masculinidad hegemónica" solamente para describir una serie de rasgos privilegiados en el orden de género hegemónico, y no para interrogar su producción, reproducción y contestación en las relaciones de género. Al igual que varias autoras feministas piensan el género como un interrogante sobre el sistema de atribuciones simbólicas basadas en la diferencia sexual que legitima las desigualdades, el concepto hegemonía fue construido por Gramsci como una noción metodológica, "como una forma de pensar la compleja interconexión entre consenso y coerción, y no como una descripción de una forma concreta de poder". La clave del concepto, entonces, radica en las posibilidades que ofrece para interrogar cómo el género, la raza, la clase, la sexualidad, otros marcadores sociales y los rasgos de la personalidad, son utilizados a nivel individual, relacional y social para legitimar (o cuestionar) la jerarquización y complementariedad del orden de género hegemónico, a nivel global, regional y local.

Desde ya, no creemos que sea necesario ni inevitable abandonar el concepto de masculinidad hegemónica. Sin embargo, su potencialidad analítica y crítica depende de la incorporación de los debates, correcciones y ampliaciones, buena parte de las cuales han sido sistematizadas en este artículo. Aunque se haya escrito en 2005, sus ideas y propuestas han demostrado no sólo ser centrales para el avance y consolidación del campo crítico sobre masculinidades, sino también sumamente necesarias. Es por ello que consideramos que la traducción de este texto puede ser un aporte importante para los estudios sobre masculinidades elaborados en nuestra región y en lengua castellana. Especialmente en un contexto donde tanto la mercantilización del conocimiento científico, como su concentración en los países anglosajones dificultan el acceso a la información y la circulación de ideas que potencian el debate crítico sobre la desigualdad de género, una realidad especialmente acuciante en nuestra región. 


\section{Introducción}

El concepto de masculinidad hegemónica, formulado en la década de 1980, ha tenido una influencia considerable en el pensamiento reciente sobre hombres, género y jerarquía social. Vinculó el emergente campo de estudio sobre masculinidades, las inquietudes sobre los hombres y los niños, la lectura feminista del patriarcado y los modelos sociológicos sobre el género. Ha sido aplicado en campos que van desde la educación y el trabajo contra la violencia, hasta la salud y la consultoría.

La búsqueda en bases de datos reveló más de 200 artículos que usan el término "masculinidad hegemónica" en sus títulos o resúmenes. Los artículos que usan una variante, o que se refieren a la masculinidad hegemónica en el texto son centenares. Varias conferencias expresan el continuo interés por el concepto ${ }^{2}$.

El concepto también ha generado serias críticas en varios sentidos: sociológicos, psicológicos, postestructuralistas y materialistas (ver Demetriou, 2001; Wetherell y Edley, 1999). Fuera del mundo académico, ha sido cuestionado, por ejemplo, en posteos de Internet, como "una invención de la psicología New Age" que intenta demostrar que los hombres son demasiado machos.

Masculinidad hegemónica es un concepto debatido. No obstante, los temas a los que alude están candentes en las luchas contemporáneas sobre el poder y el liderazgo político, la violencia pública y privada, y los cambios en la familia y la sexualidad. Si el concepto continúa demostrando ser útil, vale la pena entonces revisarlo en profundidad y reformularlo en los términos contemporáneos. En este artículo abordamos ambas tareas.

\section{Origen, formulación y aplicación}

\subsection{Origen}

El concepto de masculinidad hegemónica fue propuesto por primera vez en un informe de un trabajo de campo sobre la inequidad social en escuelas secundarias de Australia (Kessler et al., 1982); en una discusión conceptual relativa a la construcción de las masculinidades y la experiencia de los cuerpos de los hombres (Connell, 1983); y en un debate sobre el rol de los hombres en las políticas laborales australianas (Connell, 1982). El proyecto sobre las escuelas secundarias produjo evidencia empírica de jerarquías múltiples -tanto en términos de género como de claseentrelazadas con la construcción activa de proyectos de género (Connell et al., 1982).

Estos comienzos fueron sistematizados en el artículo "Towards a New Sociology of Masculinity" [Hacia una nueva sociología de la masculinidad] (Carrigan, Connell, y Lee, 1985), que criticó extensamente la literatura sobre el rol sexual masculino, y propuso un modelo de múltiples masculinidades y relaciones de poder, que luego fue integrado en la sociología de género. Las páginas de Gender and Power [Género y poder] (Connell, 1987) sobre "masculinidad hegemónica y feminidad enfatizada" fueron la fuente más citada sobre masculinidad hegemónica.

El concepto articulado por los grupos de investigación en Australia representaba una síntesis de ideas y evidencias de fuentes aparentemente disímiles, pero la convergencia de ideas no fue accidental. En otros países, investigadores y activistas también abordaban temas estrechamente vinculados; era el momento propicio para hacer una síntesis de este tipo.

2 A principios de mayo de 2005 la Universidad de Manchester, Inglaterra, celebró la conferencia "Masculinidad hegemónica y política internacional"; en 2004 se llevó a cabo en Stuttgart la una conferencia interdisciplinaria "Hegemoniale Männlichkeiten" (Dinges, Ründal y Bauer, 2004). 
Las fuentes básicas fueron las teorías feministas del patriarcado y los debates sobre el rol de los hombres en su transformación (Goode, 1982; Snodgrass, 1977). Algunos hombres de la Nueva Izquierda habían intentado organizarse para apoyar al feminismo, y pusieron de relieve las diferencias de clase en la expresión de la masculinidad (Tolson, 1977). Por otra parte, las mujeres negras -como Maxine Baca Zinn (1982), Angela Davis (1983) y bell hooks (1984)-criticaron el sesgo racista detrás de la conceptualización del poder que sólo atiende a la diferencia sexual, sentando las bases para la crítica a la universalización de la categoría de "hombre".

El término gramsciano "hegemonía" era el concepto con el que se analizaba en ese momento la estabilización de las relaciones de clase (Connell, 1977). En el marco de la teoría de sistemas duales (Eisenstein, 1979), trazar un paralelo con el problema de las relaciones de género fue fácil, a riesgo de generar un malentendido. El trabajo de Gramsci pone el foco en las dinámicas de cambio estructural que involucran la movilización y desmovilización de las clases. Sin un foco claro en la idea de cambio histórico, el concepto de hegemonía se vería reducido a un simple modelo de control cultural. En gran parte del debate sobre género los cambios históricos a gran escala no son considerados, esta es una de las fuentes de dificultades que encontrará entonces el concepto de masculinidad hegemónica.

Aun antes del movimiento de liberación de las mujeres, la literatura de la psicología social y la sociología sobre el "rol del sexo masculino" había reconocido la naturaleza social de la masculinidad y las posibilidades de cambio en la conducta de los hombres (Hacker, 1957). Durante la década de 1970 hubo una explosión de textos que criticaban agudamente las pautas del "rol masculino" como causa del comportamiento opresivo de los hombres (Brannon, 1976). La teoría crítica de los roles fue la base conceptual para el primer movimiento de hombres antisexistas, si bien las debilidades de esta teoría de los roles sexuales fueron paulatinamente reconocidas (Kimmel, 1987; Pleck, 1981). Estas incluían la confusión entre el comportamiento y la norma, el efecto homogeneizador del concepto de rol y sus dificultades para dar cuenta del poder.

Por otro lado, poder y diferencia fueron conceptos centrales en el movimiento de liberación gay, que desarrolló un sofisticado análisis de la opresión que sufren y que ejercen los hombres (Altman, 1972), mientras que algunos autores vincularon al movimiento de liberación gay con la crítica a los estereotipos de género (Mieli, 1980). La idea de la jerarquía entre masculinidades emergió directamente de las experiencias de violencia y los prejuicios que sufrían los hombres homosexuales a manos de los heterosexuales. El concepto homofobia, originado en la década de 1970, ya estaba siendo atribuido al rol masculino convencional (Morin y Garfinkle, 1978). Surgían, por entonces, perspectivas cada vez más sofisticadas sobre las relaciones ambivalentes entre los hombres gais, el patriarcado y la masculinidad convencional (Broker, 1976; Plummer, 1981).

La investigación empírica fue también una fuente importante para la formulación original. Un creciente campo de estudios documentó cómo operan a nivel local la jerarquización de género y la masculinidad en las culturas escolares (Willis, 1977), en los espacios de trabajo masculinizados (Cockburn, 1983), y en aldeas y comunidades (Herd, 1981; Hunt, 1980). Estos estudios añadieron el realismo etnográfico que faltaba en la literatura de los roles sexuales, confirmaron la pluralidad de las masculinidades y las complejidades de la construcción del género para los hombres, y dieron evidencia sobre las luchas por el dominio que está implícito en el concepto gramsciano de hegemonía.

Finalmente el concepto fue influenciado por el psicoanálisis. El propio Freud produjo las primeras biografías analíticas de hombres y, en el caso de "El hombre de los lobos", mostró cómo la personalidad adulta era un sistema bajo tensión, con contracorrientes reprimidas, pero no obliteradas. El psicoanalista Stoller popularizó el concepto de “identidad de género" y mapeó sus variaciones en el desarrollo de los niños, especialmente aquellos que derivaban en transexualidad. 
Otros, influenciados por el psicoanálisis, retomaron cuestiones como el poder masculino, el rango de posibilidades en el desarrollo del género, y la tensión y contradicción en las masculinidades convencionales (Friedman y Lerner 1986; Zaretsky 1975).

\subsection{Formulación}

Lo que emergió de este marco a mediados de la década de 1980 fue al género, lo que la investigación sobre la estructura de poder fue a la sociología política -poniendo el foco en el grupo dominante-. La masculinidad hegemónica fue entendida como el patrón de prácticas (es decir, cosas que se hacen, no sólo un conjunto de expectativas sobre el rol, o una identidad) que permite la continuidad de la dominación de los hombres sobre las mujeres.

La masculinidad hegemónica, diferenciada de otras masculinidades, especialmente de las subordinadas, no fue propuesta como la "normal" en términos estadísticos; sólo una minoría de hombres la encarnaban, pero lo cierto es que sí era "normativa". Encarnaba la forma más honorable de ser hombre, requería que los otros hombres se posicionaran en relación a ella, y legitimaba ideológicamente la subordinación global de las mujeres.

Los hombres beneficiados por el patriarcado, sin encarnar una férrea dominación masculina, podían ser considerados como masculinidades cómplices. Fue en relación a este grupo, y a la conformidad entre las mujeres heterosexuales, que el concepto hegemonía demostró más potencia. La hegemonía no significaba violencia, aunque podía ser respaldada por la fuerza, sino que refería al predominio logrado a través de la cultura, las instituciones y la persuasión.

Estos conceptos eran abstractos antes que descriptivos, definidos en términos de una lógica del sistema de género patriarcal. Asumían que las relaciones de género eran históricas y, por tanto, que las jerarquías de género están sujetas al cambio. Las masculinidades hegemónicas emergieron entonces en circunstancias específicas y estaban abiertas al cambio histórico. Más precisamente, podría haber una lucha por la hegemonía y las viejas formas de masculinidad podrían ser desplazadas por otras nuevas, esto suponía cierto optimismo en una teoría más bien pesimista. Quizás era posible que una forma más humana y menos opresiva de ser hombre se volviera hegemónica, como parte de un proceso que llevara a la abolición de las jerarquías de género.

\subsection{Aplicación}

El concepto de masculinidad hegemónica, formulado en estos términos, fue muy utilizado. Entre finales de la década de 1980 y principios de la década siguiente, la investigación sobre hombres y masculinidad se estaba consolidando como campo académico, apoyado por un conjunto de conferencias, la publicación de libros (i.e Brod, 1987), varias revistas académicas, y una creciente agenda de investigación en las ciencias sociales y humanas.

Se utilizó también en los estudios sobre educación para comprender las dinámicas de la convivencia en el aula, incluyendo patrones de bullying y de resistencia entre los niños. Fue utilizado para explorar las relaciones con el currículum y las dificultades de una pedagogía neutra en términos de género (Martino, 1995), y para comprender las estrategias y las identidades de les docentes, por ejemplo, entre profesores de educación física (Skelton, 1993).

El concepto tuvo también influencia en la criminología. Toda la información muestra que los hombres y los jóvenes cometen tanto un mayor número de crímenes convencionales, como los crímenes de mayor gravedad. Los hombres tienen, además, el monopolio virtual del crimen organizado y de guante blanco. La noción de masculinidad hegemónica ayudó también a teorizar la relación entre las masculinidades y entre diversos crímenes (Messerschmidt, 1993), y fue utilizada también en estudios sobre crímenes específicos de jóvenes y hombres, como la violación en Suiza, el asesinato en Australia, los hooligans en el fútbol y el crimen de guante blanco en Inglaterra, y la agresión violenta en Estados Unidos (Newburn and Stanko, 1994). 
El concepto también fue utilizado para estudiar las representaciones mediáticas de los hombres, por ejemplo, la relación entre el deporte y el imaginario bélico (Jansen y Sabo, 1994). Debido a que el concepto de hegemonía permitió dar sentido tanto a la diversidad como a la selectividad de las imágenes en los medios masivos, les investigadores comenzaron a mapear las relaciones entre las representaciones de diferentes masculinidades (Hanke, 1992). La industria del deporte es un foco de representaciones mediáticas sobre la masculinidad y el campo de la sociología del deporte encontró útil concepto de masculinidad hegemónica (Messner, 1992), por ejemplo, para comprender la popularidad de los deportes de contacto -que funcionan incesantemente como símbolo de la masculinidad-, y para entender la violencia y homofobia que hallamos a menudo en el ámbito deportivo (Messner y Sabo, 1990).

Los determinantes sociales de la salud de los hombres habían sido abordados anteriormente, pero el concepto de roles sexuales era demasiado difuso para ser útil, de manera que comenzaron a utilizarse los conceptos de múltiples masculinidades y de masculinidad hegemónica para comprender las prácticas masculinas y su vinculación a la salud, como la "cultura del aguante" o las conductas sexuales de riesgo (Sabo y Gordon, 1995). Los conceptos de masculinidad hegemónica y subordinada ayudaron a comprender no sólo la exposición de los hombres al riesgo sino también sus dificultades para responder a las lesiones y la incapacidad (Gerschick y Miller 1994).

El concepto también fue significativo en los estudios organizacionales, a medida que fue reconociéndose el carácter generizado de las burocracias y los espacios de trabajo. Las etnografías y estudios sobre las entrevistas laborales rastrearon la institucionalización de las masculinidades hegemónicas en organizaciones específicas (Cheng, 1996; Cockburn, 1991) y su rol en la toma de decisiones en las organizaciones (Messerschmidt, 1995). Un foco particular de estas investigaciones fue el ámbito militar, donde los patrones de masculinidad hegemónica estaban más atrincherados, pero comenzaron a problematizarse (Barrett, 1996).

Los profesionales que trabajan con hombres y niños también encontraron útil el concepto, tanto en la psicoterapia con hombres (Kupers, 1993), como en los programas de prevención de la violencia juvenil (Denborough, 1996), y los programas de educación emocional para niños (Salisbury y Jackson, 1996).

Estos son los campos primarios en los que se aplicó el concepto de masculinidad hegemónica en la década posterior a su formulación. Pero también hubo un rango más amplio de aplicación, por ejemplo, en discusiones sobre arte (Belton, 1995), en disciplinas académicas como la geografía (Berg, 1994) y el derecho (Thornton, 1989), y en discusiones generales sobre las políticas de género de los varones y la relación con el feminismo (Segal, 1990). Podemos concluir, entonces, que el análisis de múltiples masculinidades, y el concepto de masculinidad hegemónica, sirvieron como marco para buena parte del desarrollo de investigaciones sobre hombres y masculinidad, reemplazando a la teoría de los roles sexuales y a los modelos categóricos del patriarcado.

Eventualmente, la creciente investigación expandió el concepto en cuatro sentidos: documentando las consecuencias y los costos de la hegemonía, descubriendo los mecanismos de la hegemonía, mostrando una mayor diversidad de masculinidades, y rastreando los cambios en las masculinidades hegemónicas.

En relación a los costos y consecuencias, la investigación en criminología mostró que ciertos patrones de agresión, podrían entenderse no como un efecto causado mecánicamente por la masculinidad hegemónica, sino como parte de la búsqueda de la hegemonía (Bufkin, 1999; Messerschmidt, 1997). Además, la investigación pionera de Messner (1992) mostró que la puesta en acto de la masculinidad hegemónica en los deportes profesionales, mientras reproduce marcadas jerarquías, también genera un costo considerable a los vencedores, en términos de daño emocional y psíquico. 
La investigación ha sido fructífera al revelar los mecanismos de la hegemonía. Algunos de ellos son muy visibles, como la "espectacularización" de la masculinidad en los deportes televisados (Sabo y Jansen, 1992), y los mecanismos sociales de "censura" sobre los grupos subordinados (Roberts, 1993) -desde las burlas informales de los niños a la criminalización de la conducta homosexual-. Sin embargo, otros mecanismos de la hegemonía operan en la invisibilidad, evitando que las formas dominantes de masculinidad sean expuestas a la censura (Brown, 1999). Al examinar la cobertura mediática de la masacre de Columbine, Consalvo (2003) notó que la cuestión de la masculinidad fue eludida por los medios, lo que dejó a la figura del "monstruo" como la única forma de representar a los atacantes.

La investigación internacional ha confirmado la percepción inicial de que los órdenes de género construyen múltiples masculinidades. Valdés y Olavarría (1998) mostraron que incluso en un país culturalmente homogéneo como Chile, no hay una única masculinidad, dado que los patrones varían según la clase y la generación. En Japón, otro país considerado como homogéneo, se rastreó la "emergencia de diversas masculinidades" tanto en la historia reciente, a partir de los importantes cambios en las prácticas de cuidado infantil (Ishii-Kuntz, 2003); como en instituciones particulares, como el ejército (Higate, 2003).

En la más bella etnografía moderna sobre la masculinidad, Gutmann (1996) estudió un caso donde hay una clara definición de la identidad pública masculina, el "machismo" mexicano. Gutmann muestra cómo el imaginario del machismo fue desarrollado históricamente y ligado al desarrollo del nacionalismo mexicano, enmascarando la enorme complejidad de las vidas reales de los hombres mexicanos. Gutmann ensaya cuatro patrones de masculinidad en los barrios de clase obrera urbana que estudia, insistiendo en que pueden ser segmentados por otras divisiones sociales y son constantemente renegociados en la vida cotidiana.

Finalmente, un considerable cúmulo de investigaciones muestran que las masculinidades no son sólo diferentes, sino que también están sujetas al cambio. Los desafíos a la hegemonía son comunes, y también lo son los ajustes de cara a estos desafíos. Morrell (1998) reúne la evidencia sobre las transformaciones del género en el sur de África asociadas al fin del Apartheid, un sistema de segregación y competencia entre patriarcados. Ferguson (2001) rastrea el declive de los ideales de masculinidad de larga duración en Irlanda -el cura célibe y el hombre de familia trabajador- y su reemplazo por modelos modernizados y orientados al mercado. Dasgupta (2000) rastrea las tensiones del modelo japonés de "masculinidad asalariada", especialmente luego de la "economía de burbuja" de la década de 1980, donde apareció la figura cultural del "salaryman escaping". Taga (2003) documenta diversas respuestas al cambio entre los jóvenes de clase media en Japón, incluyendo nuevas opciones para la convivencia con mujeres. Meuser (2003) rastrea el cambio generacional en Alemania, en parte debido a las respuestas de los hombres frente a los cambios de las mujeres. Muchos jóvenes (aunque no todos), al esperar que las mujeres rechacen relaciones patriarcales, están elaborando sus propios "igualitarismos pragmáticos". Morris y Evans (2001), en el estudio de las imágenes rurales de la masculinidad y la feminidad en Bretaña, encuentran un ritmo de cambio más lento, pero una creciente sutileza y fragmentación en la representación de la masculinidad hegemónica.

Desde mediados de 1980 a principios del 2000, el concepto de masculinidad hegemónica pasó entonces de un modelo conceptual con una base empírica bastante estrecha, a ser un marco ampliamente usado para investigar y debatir sobre hombres y masculinidades. El concepto fue aplicado en diversos contextos culturales y a un considerable rango de asuntos prácticos. No es sorprendente, entonces, que el concepto haya generado críticas, y a esto nos dedicaremos ahora. 


\section{Críticas}

Desde que comenzó el debate sobre el concepto a principios de la década de 1990, las principales críticas han sido cinco. En esta sección, evaluamos cada crítica, esperando descubrir qué vale la pena retener de la concepción original de masculinidad hegemónica y qué necesita ser reformulado.

\subsection{El concepto subyacente de masculinidad}

Se argumentó desde dos puntos de vista diferentes, el realista y el postestructuralista, que el concepto subyacente de masculinidad era defectuoso. Para Collinson y Hearn (1994) y Hearn (1996, 2004) el concepto de masculinidad es confuso, incierto en su significado y tiende a quitar el énfasis sobre las cuestiones del poder y la dominación. Es en última instancia innecesario para entender y cuestionar el poder de los hombres. El concepto de múltiples masculinidades tiende a producir una tipología estática.

Para Petersen (1998, 2003), Collier (1998), y Maclnnes (1998) el concepto de masculinidad es defectuoso porque esencializa la personalidad de los hombres o impone una falsa unidad en una realidad fluida y contradictoria. Algunas versiones de este argumento critican a las investigaciones sobre masculinidad porque no han adoptado las herramientas específicas del postestructuralismo que, por ejemplo, hubieran enfatizado la construcción discursiva de las identidades (Whitehead, 2002). El concepto de masculinidad es criticado por estar enmarcado en una concepción heteronormativa del género que esencializa la diferencia macho-hembra e ignora la diferencia y la exclusión al interior de las categorías de género. Se ha dicho que el concepto de masculinidad parte de una lógica dicotómica entre el sexo (biológico) y el género (cultural) y por tanto margina o naturaliza el cuerpo.

No sería responsable negar que en la vasta literatura dedicada a la masculinidad hay en gran medida una confusión conceptual, así como una fuerte dosis de esencialismo. Ciertamente, esto es común en los abordajes de la masculinidad de la psicología pop, en el movimiento mitopoético de hombres y en las interpretaciones periodísticas de las investigaciones sobre las diferencias sexuales biológicas. Otra cuestión es, sin embargo, afirmar que el concepto de masculinidad, o el uso que les investigadores hacen de él, son confusos o esencialistas.

La investigación sobre masculinidades en ciencias sociales y humanidades ha florecido durante los últimos 20 años precisamente a causa de que el concepto subyacente no es reificante ni esencialista. La idea de que el concepto de masculinidad esencializa u homogeneiza, es bastante difícil de reconciliar con la gran multiplicidad de construcciones sociales que les etnógrafes e historiadores han documentado gracias a este concepto. El hecho de que se haya investigado sobre masculinidades encarnadas por personas con cuerpos femeninos (Halberstam, 1998; Messerschmidt, 2004), lo aleja más aún del esencialismo. La masculinidad no es una entidad fija incrustada en el cuerpo o en los rasgos de la personalidad de los individuos. Las masculinidades son configuraciones de prácticas que se llevan a cabo en la acción social y, por ello, pueden variar de acuerdo a las relaciones de género en un contexto social particular.

La idea de que el reconocimiento de múltiples masculinidades necesariamente se transforma en una tipología estática, no parece haber surgido del desarrollo de las investigaciones. Un ejemplo paradigmático es la etnografía mexicana de Gutmann (1996) mencionada más arriba. Gutmann consigue proponer diferentes categorías de masculinidad -por ejemplo, el macho y el mandilónmientras reconoce y muestra en detalle que no se trata de identidades unívocas sino siempre relacionales y constantemente atravesadas por otras divisiones y proyectos. Las observaciones de Warren (1997) en una escuela primaria nos dan otro ejemplo. Allí encuentra diferentes construcciones de masculinidad que generan efectos en la convivencia en el aula, aun cuando 
muchos niños no encajen en las grandes categorías; de hecho, los niños muestran relaciones complejas de apego y rechazo a esas categorías.

Aunque la idea de que el concepto de género implica heteronormatividad sea ahora una crítica frecuente (Hawkesworth, 1997), también es una idea cuestionada (Scott, 1997). Si bien identifica correctamente un problema en las categorías de género, no se trata de una crítica válida para un modelo relacional del género (p.ej. Connell, 2002; Walby, 1997), ni para los abordajes históricos donde la construcción de las categorías de género es el objeto de investigación. En el desarrollo del concepto de masculinidad hegemónica, las divisiones entre hombres -especialmente la exclusión y la subordinación de los hombres homosexuales- fueron cuestiones centrales (Carrigan, Connell y Lee, 1985). Desde entonces, la vigilancia de la heterosexualidad ha sido un tema central en las discusiones sobre la masculinidad hegemónica.

La idea de que el concepto de masculinidad margina o naturaliza el cuerpo (porque se supone que se basa en la dicotomía sexo-género) es quizás la afirmación más sorprendente en esta crítica, porque la relación entre cuerpos y procesos sociales ha sido uno de los temas centrales de la investigación sobre masculinidad desde sus comienzos. Uno de los primeros y más influyentes programas de investigación en el nuevo paradigma fue el abordaje de Messner (1992) sobre la masculinidad de atletas profesionales, donde estudió cómo los hombres usan sus "cuerpos como armas" y el daño a largo plazo que sufren en ellos. La construcción de la masculinidad en un contexto de discapacidad (Gerschick y Miller, 1994), los cuerpos laboriosos de los hombres de clase trabajadora (Donaldson, 1991), la salud y enfermedad de los hombres (Sabo y Gordon, 1995), y la violencia entre niños (Messerschmidt, 2000), están entre los temas de investigación que muestran cómo los cuerpos son afectados por los procesos sociales. La discusión teórica ha explorado la relevancia de la "nueva sociología del cuerpo" en relación a la construcción de la masculinidad (p.ej. Connell, 1995, cap. 2).

Las críticas al concepto de masculinidad tienen más sentido cuando apuntan a la tendencia, tanto de la investigación como de la literatura popular, a dicotomizar las experiencias de los varones y las mujeres. Como Brod (1994) observa certeramente, hay una tendencia en el campo de los "men's studies" a presumir "esferas separadas", a proceder como si las mujeres no fueran parte relevante del análisis y, por tanto, a analizar las masculinidades sólo mirando a los hombres y a las relaciones entre hombres. Como también afirma Brod, esto no es inevitable. La solución reside en utilizar un abordaje relacional del género, no en abandonar los conceptos de género o masculinidad.

\subsection{Ambigüedad y superposición}

Las críticas tempranas del concepto plantearon el interrogante sobre quién, de hecho, representa la masculinidad hegemónica. Es sabido que muchos hombres que tienen gran poder social no encarnan una masculinidad ideal. Por otro lado, Donaldson (1993) remarca que no parece haber mucha sustancia masculina en esos hombres identificados por los investigadores como modelos hegemónicos. Discute el caso del "iron man" australiano, campeón de surf descrito por Connell (1990), un popular ejemplo de masculinidad hegemónica. Pero el estatus hegemónico regional de este joven, de hecho, le impide hacer las cosas que su grupo de pares local define como masculinas -descontrolarse, alardear, conducir borracho, meterse en peleas y defender su propio prestigio-.

Martin (1998) critica el concepto porque conduce a aplicaciones inconsistentes, a veces referencia a un tipo fijo de masculinidad, y otras veces refiere a cualquier tipo dominante en un particular tiempo y espacio. De forma similar, Wetherell y Edley (1999) sostienen que el concepto falla porque no especifica cómo se ve en la práctica la conformidad con la masculinidad hegemónica. $Y$ Whitehead (1998:58; 2002:93), sugiere que hay una confusión sobre quién es realmente un hombre 
hegemónicamente masculino - ¿es John Wayne o Leonardo Di Caprio; Mike Tyson o Pelé?, ¿o tal vez, en distintos momentos, todos ellos? - y también sobre quién puede llevar a cabo prácticas hegemónicas.

Pensamos que las críticas han apuntado correctamente las ambigüedades en los usos. Es deseable eliminar cualquier uso de la masculinidad hegemónica como un modelo fijo y transhistórico. Este uso traiciona la historicidad del género e ignora la gran evidencia del cambio en las definiciones sociales de la masculinidad.

Pero en otros aspectos, puede ser importante reconocer la ambigüedad en los procesos de género como un mecanismo de la hegemonía. Consideremos cómo una definición idealizada de masculinidad se constituye en el proceso social. A un nivel social más amplio (que vamos a llamar "regional") hay una circulación de modelos de conducta masculina admirada, que pueden ser exaltados por iglesias, narrados por medios de comunicación o celebrados por el Estado. Estos modelos refieren a, pero también distorsionan en varios sentidos, las realidades cotidianas de la práctica social. Un ejemplo clásico es la celebración soviética del trabajador industrial Stakhanovite, llamados así por el trabajador de las minas de carbón Aleksandr Stakhanov, que en 1935 batió un récord mundial cortando 102 toneladas de carbón en un solo día, lanzando una disputa por superar el récord. Parte de la distorsión aquí, fue que los famosos "trabajadores de choque" lograron sus números con una gran cantidad de ayuda no reconocida de sus compañeros de trabajo.

Por lo tanto, pueden construirse masculinidades hegemónicas que no correspondan estrechamente con la vida de ningún hombre real. Aun así, estos modelos expresan, en varios sentidos, ideales, fantasías y deseos muy difundidos; y proveen modelos de relaciones con las mujeres y soluciones a los problemas de las relaciones de género. Asimismo, se articulan imprecisamente con la constitución práctica de las masculinidades como formas de vivir cotidianamente en las circunstancias locales. Al hacerlo, contribuyen a la hegemonía en un nivel social amplio del orden de género como un todo. No sorprende que los hombres que funcionan como ejemplos a nivel regional, como el "iron man" que discute Donaldson, muestren contradicciones.

A nivel local, los patrones hegemónicos de masculinidad están incorporados en ambientes sociales específicos, tales como organizaciones formales. Hay, por ejemplo, patrones bien definidos de masculinidad empresarial en las corporaciones británicas estudiadas por Roper (1994) y Wajcman (1999). Los modelos hegemónicos de masculinidad legitimados socialmente también se ponen en juego en las familias. Por ejemplo, las estrategias de género de los hombres moldean las negociaciones sobre el trabajo doméstico y la "segunda jornada" en las familias estadounidenses estudiadas por Hochschild (1989). Los patrones hegemónicos de masculinidad están al mismo tiempo presentes y cuestionados a medida que los niños crecen. El género se hace en las escuelas y vecindarios a través de la estructura del grupo de pares, el control del espacio en la escuela, los patrones en las citas, el discurso homofóbico y el acoso (Mac an Ghaill 1994; Thorne 1993). En ninguno de estos casos esperaríamos que la masculinidad hegemónica destaque como un patrón claramente definido separado de los otros. Si la hegemonía es efectiva, es muy probable que haya un grado de superposición o de confusión entre las masculinidades hegemónicas y cómplices.

La confusión entre masculinidades puede también verse en los términos de los agentes sociales que construyen masculinidades. Cavender (1999) muestra cómo los modelos hegemónicos masculinos fueron construidos de forma diferente en largometrajes en la década de 1940 y en la década de 1980. No se trata sólo de los personajes escritos en los guiones. La práctica a nivel local -esto es, la interacción cara a cara que supone rodar un largometraje como actor- en última instancia construye modelos de fantasía de masculinidad hegemónica (en este caso, detectives) a nivel social o regional (exploraremos esta cuestión de las relaciones entre niveles en la sección Reformulación de este artículo). 


\subsection{El problema de la reificación}

También se ha argumentado desde diferentes puntos de vista, que el concepto masculinidad hegemónica se reduce, en la práctica, a una reificación del poder o la toxicidad. Holter $(1997,2003)$, en la más sofisticada de todas las críticas, argumenta que el concepto construye el poder masculino desde la experiencia directa de las mujeres, en vez de hacerlo desde la base estructural de la subordinación de las mujeres. Holter cree que debemos distinguir entre "patriarcado", la estructura duradera de subordinación de las mujeres, y "género", un sistema específico de intercambio que emerge en el contexto del capitalismo moderno. Es un error tratar la jerarquía de masculinidades construida al interior de las relaciones de género en una continuidad lógica con la subordinación patriarcal de las mujeres. Holter (1997), elocuentemente, apunta a la evidencia de encuestas noruegas que muestran que las identidades de género de los hombres no se corresponden directamente con las prácticas igualitarias, como las actitudes hacia la violencia.

Holter $(1997,2003)$ ciertamente está en lo correcto al plantear que es un error deducir relaciones entre masculinidades del ejercicio directo del poder personal de los hombres sobre las mujeres. En última instancia, también deberíamos tomar en cuenta la institucionalización de las equidades de género, el rol de las construcciones culturales y la intersección de las dinámicas de género con la raza, la clase y la región.

Es, de hecho, la investigación en estos asuntos la que muestra que el concepto masculinidad hegemónica no está atrapado en la reificación. Entre los fructíferos estudios sobre masculinidades institucionales están aquellos que revelan variaciones muy sutiles, por ejemplo, entre las diferentes ramas de una sola fuerza militar, como la marina estadounidense (Barrett, 1996). Existen estudios de masculinidades hegemónicas específicamente locales construidas en espacios como los pubs rurales neozelandeses que muestran la interrelación de la masculinidad con la identidad rural (Campbell, 2000). Otra investigación, que estudia específicamente las aulas (Martino, 1995; Warren, 1997), muestra la refinada producción y negociación de las masculinidades (y feminidades) como configuraciones de las prácticas.

Collier (1998) critica el concepto de masculinidad hegemónica por su uso típico para narrar la violencia y el crimen. En el "giro hacia la masculinidad" de la criminología, Collier sugiere que la masculinidad hegemónica llegó a ser asociada solamente con características negativas que describen a los hombres como no emocionales, independientes, no cuidadores, agresivos y desapasionados -que son vistas como las causas del comportamiento criminal-. De forma similar, Martin (1998:473) observa una deriva hacia la concepción de la masculinidad hegemónica no sólo como un tipo, sino como un tipo negativo, por ejemplo, al decir que "la defensa de la tenencia de armas es una defensa de la masculinidad hegemónica". Esta crítica tiene fuerza. Nos conduce al preciso análisis de McMahon (1993) sobre el psicologicismo en las discusiones sobre hombres y masculinidad. El comportamiento de los hombres es reificado en un concepto de masculinidad que, entonces, en un argumento circular, se vuelve la explicación (y la excusa) para el comportamiento. Esto puede ser observado en varias discusiones sobre la salud de los hombres y los problemas de la educación de los niños -y de hecho, en cualquiera de los problemas contemporáneos reunidos bajo el rótulo de una "crisis de la masculinidad". En la psicología pop, la invención de nuevos tipos de personalidad es endémica (el macho alfa, el hombre sensible de la new-age, el hombre peludo, el nuevo muchacho, el "niño rata", etc.). En este contexto, la masculinidad hegemónica se puede volver un sinónimo que suena científico para un tipo rígido, dominante, sexista, de "macho" (en su uso anglosajón, ver Mosher y Tomkins, 1998).

Dado que el concepto de masculinidad hegemónica está basado en las prácticas que permiten la continuidad de la dominación colectiva de los hombres sobre las mujeres, no sorprende que, en 
algunos contextos, la masculinidad hegemónica, de hecho, refiera al involucramiento de los varones en prácticas tóxicas -incluyendo la violencia física- que estabiliza la dominación de género en un contexto particular. De todas formas, la violencia y otras prácticas nocivas no siempre son las características que la definen, ya que la hegemonía tiene numerosas configuraciones. De hecho, como observan irónicamente Wetherell y Edley (1999), una de las más efectivas formas de ser un hombre en ciertos contextos locales es distanciándose de la masculinidad hegemónica local.

Collier (1998) ve como un defecto crucial que el concepto de masculinidad hegemónica excluya el comportamiento "positivo" de los hombres -esto es, comportamientos que puedan servir a los intereses o deseos de las mujeres. Esto difícilmente es un problema una vez que trascendemos una teoría rígida de los rasgos de personalidad. La mayor parte de los abordajes de la masculinidad hegemónica incluyen estas acciones "positivas", como llevar el salario a casa, sostener una relación sexual y ser padre. De hecho, es difícil ver cómo el concepto de hegemonía podría ser relevante si las únicas características del grupo dominante fueran la violencia, la agresión y el egoísmo. Estas características pueden significar dominación, pero difícilmente constituyan hegemonía -una idea que implica ciertas nociones de consentimiento y participación de los grupos subalternos.

Collier (1998:21) remarca acertadamente que lo que está siendo realmente discutido en muchos abordajes de la masculinidad hegemónica y el crimen (y podemos agregar la salud y la educación), es "un rango de ideologías populares sobre cuáles son las características ideales o reales del `ser un hombre'". Lo que Collier olvida, no obstante, es que la investigación sofisticada consistentemente continúa explorando la relación de esas ideologías con la vida cotidiana de hombres y niños incluyendo los equívocos, las tensiones y las resistencias.

Son las relaciones prácticas de los hombres y niños con las imágenes colectivas o los modelos de masculinidad, más que sus simples reflejos, las que son centrales para comprender las consecuencias generizadas en la violencia, la salud y la educación. Esto ha sido evidente desde la formulación de Messerschmidt (1993) de la idea de que diferentes crímenes son usados por diferentes hombres en la construcción de las masculinidades. Para Collier esta idea es inaceptable, sea por tautológica y universalizante, o por ser demasiado abarcativa en lo que explica. Pero no hay nada sorprendente en la idea de la generación de diversas prácticas a partir de modelos culturales comunes; no hay nada conceptualmente universalizante en la idea de masculinidad hegemónica. La coordinación y la regulación suceden en la cotidianeidad de las prácticas sociales de colectividades, instituciones, y sociedades completas. El concepto de masculinidad hegemónica no pretende ser ni un comodín ni una causa primordial; es una forma de dar cuenta de cierta dinámica en el proceso social.

\subsection{El sujeto masculino}

Diversos autores argumentaron que el concepto de masculinidad hegemónica está basado en una teoría del sujeto insatisfactoria. Wetherell y Edley (1999) desarrollan esta crítica desde el punto de vista de la psicología discursiva, argumentando que la masculinidad hegemónica no puede ser entendida como la estructura de personalidad establecida de ningún grupo de hombres. Debemos preguntarnos "cómo los hombres se conforman en relación a un ideal y se vuelven tipos cómplices o resistentes, sin que nadie logre encarnar exactamente ese ideal” (p. 337).

Wetherell y Edley (1999) sugieren que deberíamos entender las normas hegemónicas como definición de una posición de sujeto en el discurso que es estratégicamente tomada por los hombres en circunstancias particulares. La masculinidad hegemónica tiene múltiples significados -un punto que algunos autores han criticado, pero que Wetherell y Edley toman como un punto de partida positivo-. Los hombres pueden adoptar la masculinidad hegemónica cuando es deseable, pero los 
mismos hombres pueden distanciarse estratégicamente de la masculinidad hegemónica en otros momentos. Consecuentemente, "la masculinidad" no representa un cierto tipo de hombre, sino una manera en que los hombres se posicionan a sí mismos a través de prácticas discursivas.

Whitehead (2002:93) plantea que el concepto de masculinidad hegemónica sólo puede "ver" estructura, haciendo invisible al sujeto: "El individuo está perdido, o en términos althusserianos, sujeto a un aparato ideológico y a un deseo innato de poder". Para Whitehead, el concepto falla en especificar cómo y por qué algunos hombres heterosexuales legitiman, reproducen y generan su dominación, y lo hacen como una minoría social de cara a las mujeres y otros hombres. Consecuentemente, el uso del concepto conlleva a "una confusión, en la fusión de masculinidades fluidas con la estructura general y, en última instancia, en 'estructuras dinámicas abstractas'" (Whitehead, 2002:93-94). Para Whitehead, es preferible concentrarse en el discurso como el medio por el cual los hombres se conocen a sí mismos, practican su "trabajo identitario", y ejercen el poder de género y la resistencia.

Una crítica relacionada a esta, deriva del psicoanálisis. De acuerdo a esta mirada, el modelo de masculinidad hegemónica supone un sujeto unitario; pero la psicología profunda revela un sujeto con muchas capas o escindido (Collier, 1998; Jefferson, 1994). Jefferson (2002) critica la mirada "sobre-socializada del sujeto masculino" en los estudios de masculinidad, que ha resultado en una falta de atención sobre cómo los hombres se relacionan con la masculinidad hegemónica. Dadas las múltiples masculinidades, Jefferson considera que las investigaciones deben indagar "cómo los hombres, con sus biografías únicas y particulares formaciones psíquicas, se relacionan concretamente con estas diversas masculinidades" (p. 73). Jefferson sugiere que los niños y los hombres escogen las posiciones discursivas que los ayudan a evitar la ansiedad y los sentimientos de impotencia.

El argumento de la psicología discursiva es bien recibido y se integra bien con una aproximación fructífera de la investigación. Un buen ejemplo es un estudio de Lea y Auburn (2001) sobre la historia relatada por un violador convicto en un programa para agresores sexuales, que muestra cómo el narrador se mueve entre ideologías contradictorias sobre la interacción sexual, de manera que reduce su responsabilidad por la violación. Otro ejemplo es la exploración de Archer (2001) sobre el discurso identitario de jóvenes musulmanes británicos, donde muestra cómo usan un modelo específico de masculinidad hegemónico ("poderoso, patriarcal") para posicionarse a sí mismos en relación a hombres afro-caribeños, hombres blancos y mujeres musulmanas. De este trabajo podemos aprender no sólo cómo las masculinidades se construyen en el discurso, sino también cómo son utilizadas en el discurso. Específicamente, cómo una versión localmente hegemónica de la masculinidad puede ser utilizada para promover el respeto por uno mismo frente al descrédito, por ejemplo, de la denigración racista.

Las perspectivas discursivas enfatizan la dimensión simbólica, mientras que el concepto de masculinidad hegemónica fue formulado en una concepción multidimensional del género. Aunque cualquier especificación de la masculinidad hegemónica involucra típicamente la formulación de ideales culturales, no debe ser vista sólo como una norma cultural. Las relaciones de género también son construidas a través de prácticas no discursivas, incluyendo el trabajo asalariado, la violencia, la sexualidad, el trabajo doméstico y el cuidado de niñes, así como a través de acciones rutinarias e irreflexivas.

Reconocer las dimensiones no discursivas e irreflexivas del género nos da un sentido de los límites de la flexibilidad discursiva. La existencia de estos límites es potentemente argumentada por el estudio de Rubin (2003) sobre los hombres trans. Una persona no es libre de adoptar cualquier posición de género en la interacción, simplemente como una práctica discursiva o reflexiva. Las posibilidades están limitadas fuertemente por la encarnación (embodiment), por las historias 
institucionales, las fuerzas económicas y por las relaciones personales y familiares. Los costos de hacer ciertas elecciones discursivas pueden ser excesivamente altos -como muestra la alta tasa de suicidios entre personas trans-.

Las limitaciones también pueden emerger de la propia persona. Los informantes de Rubin (2003) actúan así, y enfrentan los costos, por una inconmovible convicción de ser hombres -a pesar de comenzar con cuerpos femeninos y haber sido criados como niñas-. Ellos están convencidos de ser sujetos unitarios, aunque vivan una contradicción que parece ejemplificar el argumento de Jefferson $(1994,2002)$ del sujeto escindido. Estamos de acuerdo con Jefferson en que la práctica y la teoría psicoanalítica son fuentes importantes para comprender el asunto complejo de la práctica del género. De todas formas, el particular abordaje psicoanalítico de Jefferson tiene algunos problemas (Messerschmidt, 2005), y es importante reconocer la diversidad y la riqueza de la tradición psicoanalítica. Abordajes como el psicoanálisis existencialista de Sartre son útiles para entender las masculinidades como proyectos y una identidad masculina como un logro siempre provisional en el trayecto de la vida. El psicoanálisis adleriano, con su énfasis en las consecuencias emocionales de las relaciones de poder generizadas en la infancia, hace emerger la idea de la "protesta masculina", que continúa resonando en las discusiones contemporáneas de la juventud marginalizada. El concepto de masculinidad hegemónica originalmente fue formulado considerando los argumentos psicoanalíticos sobre el carácter contradictorio y multifacético de la personalidad, la disputa cotidiana en la vida social, y la mixtura de estrategias necesarias en cualquier intento por sostener la hegemonía (Carrigan, Connell y Lee, 1985; Connell, 1987). De alguna manera es irónico que el concepto sea criticado por sobresimplificar al sujeto, pero es verdad, por supuesto, que a menudo ha sido empleado de forma simplificada.

¿El concepto borra necesariamente al sujeto? Estamos profundamente en desacuerdo con el planteo de Whitehead (2002), sobre que el concepto de masculinidad hegemónica se reduce a un determinismo estructural. La masculinidad es definida como una configuración de la práctica organizada en relación a la estructura de relaciones de género. La práctica social humana crea relaciones de género en la historia. El concepto de masculinidad hegemónica lleva incorporada una mirada del género históricamente dinámica, en la cual es imposible borrar al sujeto. Es por ello que los estudios de historias de vida se han convertido en un género característico sobre masculinidades hegemónicas.

El concepto homogeneiza al sujeto sólo si es reducido a una única dimensión de las relaciones de género (usualmente, la simbólica), y si es tratado como la concreción de una norma. Tan pronto como se reconozca la multidimensionalidad de las relaciones de género (Connell, 2002) y las tendencias a la crisis al interior de las relaciones de género (Connell, 1995), es imposible considerar al sujeto, constituido en esas relaciones, como unitario. Hay, por supuesto, diferentes formas de representar la incoherencia del sujeto. El lenguaje conceptual del postestructuralismo es sólo un camino para ello; el psicoanálisis y el modelo de la agencia dentro de estructuras sociales contradictorias proveen otros.

\subsection{El patrón de las relaciones de género}

En las teorías sociales sobre género ha habido una tendencia hacia el funcionalismo. Esto es, ver a las relaciones de género como un sistema autosuficiente y que se reproduce a sí mismo, explicando cada elemento en términos de su función en la reproducción del todo. Hawkesworth (1997) detecta esta tendencia en la mayor parte de las teorías de género modernas, y la última intervención de Bourdieu (2001) para explicar la dominación masculina le ha dado un nuevo soplo de vida al funcionalismo en el análisis del género. 
El dominio de los hombres y la subordinación de las mujeres constituyen un proceso histórico, no un sistema que se reproduce a sí mismo. "La dominación masculina" está abierta al cuestionamiento y requiere un esfuerzo considerable para mantenerse. Aunque este punto fue sostenido en las primeras formulaciones del concepto de masculinidad hegemónica, no es solamente una idea teórica. Existen trabajos detallados que muestran las tácticas de sostenimiento del dominio masculino a través de la exclusión de las mujeres, desde el trabajo de Bird (1996) sobre homosocialidad, hasta la investigación sobre organizaciones de Collinson, Knights y Collison (1990), Cockburn (1991) y Martin (2001).

Existe considerable evidencia de que la masculinidad hegemónica no es una forma que se autoreproduce, sea a través del habitus o cualquier otro mecanismo. Para sostener un patrón dado de hegemonía se requiere tanto la vigilancia de los varones como la exclusión o el descrédito de las mujeres. La evidencia de tales mecanismos, va desde la desvalorización de las decisiones "suaves" en el "áspero" mundo de las relaciones internacionales, las amenazas a la seguridad y la guerra (Hooper, 2001), pasando por las agresiones y asesinatos homofóbicos (Tomsen, 2002), hasta la burla en las escuelas hacia los niños por "mariquitas" (Kimmel y Mahler, 2003; Messerschmidt, 2000).

En la cuidadosa crítica del concepto masculinidad hegemónica que hace Demetriou (2001) se reconoce la historicidad del género, sin embargo, sugiere que ha ocurrido otro tipo de simplificación. Este autor identifica dos formas de hegemonía, interna y externa. La "hegemonía externa" refiere a la institucionalización de la dominación de los hombres sobre las mujeres; la "hegemonía interna" refiere a la primacía social de un grupo de hombres sobre otros. Demetriou sostiene que la relación entre estas dos formas es poco clara en la formulación original del concepto e inespecífica en sus usos actuales. Además, la hegemonía interna ha sido típicamente entendida de forma "elitista". Es decir, las masculinidades subordinadas y marginalizadas son consideradas como si no tuvieran ningún impacto en la construcción de la masculinidad hegemónica. Las masculinidades no hegemónicas existen en tensión, pero nunca penetran o impactan con la masculinidad hegemónica. Esta es, entonces, una representación dualista de las masculinidades.

Demetriou sostiene que una conceptualización como esta pierde de vista el "pragmatismo dialéctico" de la hegemonía interna, a través de la cual la masculinidad hegemónica se apropia de otras masculinidades en todo aquello que sea útil para continuar la dominación. El resultado de esta dialéctica no es un patrón unitario de masculinidad hegemónica sino un "bloque histórico" que incluye el entretejimiento de múltiples patrones cuya hibridación es la mejor estrategia posible para la hegemonía externa. Así tiene lugar un constante proceso de negociación, traducción y reconfiguración.

Esta conceptualización conlleva una mirada diferente del cambio histórico en las masculinidades. La masculinidad hegemónica no se adapta simplemente a las cambiantes condiciones históricas. En cambio, el bloque hegemónico masculino es un híbrido cuya apropiación de diversos elementos lo hace "capaz de reconfigurarse a sí mismo y adaptarse a las especificidades de nuevas coyunturas históricas" (Demetriou, 2001:355). Como un ejemplo de este proceso, Demetriou analiza la creciente visibilidad cultural de la masculinidad gay en sociedades occidentales. Esto ha hecho posible para ciertos hombres heterosexuales apropiarse de "fragmentos" de los estilos y prácticas de hombres gais, y construir una nueva configuración híbrida de la práctica de género. Esta apropiación difumina la diferencia, pero no socava al patriarcado.

La conceptualización de Demetriou (2001) del pragmatismo dialéctico en la "hegemonía interna" es útil, y argumenta convincentemente que ciertas representaciones de la masculinidad, y las prácticas cotidianas de género de algunos hombres heterosexuales, se han apropiado de aspectos de las masculinidades gais. Claramente, prácticas masculinas específicas pueden ser apropiadas dentro de otras masculinidades, creando un híbrido (como el estilo hip-hop y el lenguaje adoptado por algunos 
adolescentes blancos de clase trabajadora, y el singular estilo combinado de los "clones" de gais). Sin embargo, no estamos convencidos de que la hibridación que Demetriou describe es hegemónica, al menos más allá de un sentido local. Aunque la masculinidad y la sexualidad gay son crecientemente visibles en las sociedades occidentales -somos testigos de la fascinación con los personajes gais de los programas de televisión Six feet under, Will and Grace y Queer eye for the straight guy-, hay pocos motivos para pensar que la hibridación se ha vuelto hegemónica a un nivel regional o global. El concepto de bloque hegemónico pone en foco el asunto de las múltiples masculinidades hegemónicas. Jefferson (2002:71) y otros, han criticado la tendencia a hablar sólo de un patrón -"masculinidad hegemónica es siempre usado en singular". Hay una paradoja aquí. Dado que cada etnografía descubre una cultura de género distintiva, cada estudio de historia de vida devela trayectorias únicas en las vidas de los hombres, y cada análisis estructural define nuevas intersecciones de raza, clase, género y generación, es lógicamente posible definir "mil y una" variaciones de la masculinidad (Meuser y Behnke, 1998). Esto seguramente también aplica a quienes pretenden la hegemonía. Este punto es fuertemente sostenido por el mapeo de Messner (1997) sobre las políticas de masculinidad en los Estados Unidos, el cual revela un rango de movimientos con agendas contrastantes. Incluso al examinarlos detenidamente, la mayor parte de estos movimientos se proclaman como el modo en que los hombres piensan y viven. Sea cual sea la diversidad empírica de las masculinidades, la disputa por la hegemonía implica que la jerarquía de género no tiene nichos múltiples en su cumbre. Volveremos sobre este punto, que es importante para entender las políticas de género.

\section{Revisión y reformulación}

Hemos hilvanado estas líneas juntas para sugerir cómo el concepto de masculinidad hegemónica debería ser reformulado. Indicaremos aquellos aspectos del concepto original que se sostienen a la luz de las investigaciones y las críticas, aquellos aspectos que deberían ser descartados, y (con mayor detalle) aquellas áreas donde el concepto necesita una reactualización.

\subsection{Lo que debe conservarse}

El aspecto fundamental del concepto sigue siendo la combinación de la pluralidad de las masculinidades y la jerarquía de las masculinidades. Esta idea básica se ha mantenido en pie en 20 años de experiencia en la investigación. Se han identificado múltiples patrones de masculinidad en diferentes estudios, en una variedad de países y en diferentes instituciones y ámbitos culturales. Es también un hallazgo de la investigación muy difundido que ciertas masculinidades son socialmente más centrales, o están más asociadas a la autoridad y el poder social que otras. El concepto masculinidad hegemónica supone la subordinación de masculinidades no hegemónicas, y este proceso ha sido bien documentado en diferentes ámbitos a nivel internacional.

También tiene un buen sustento la idea de que la jerarquía de masculinidades es un patrón de hegemonía, no un patrón de simple dominación basada en la fuerza. El consentimiento cultural, la centralidad discursiva, la institucionalización, y la marginalización o deslegitimación de las alternativas son aspectos de las masculinidades socialmente dominantes ampliamente documentados.

También tiene un buen sustento la idea original de que la masculinidad hegemónica no necesita ser el patrón más común en la vida cotidiana de hombres y niños. En cambio, la hegemonía funciona, en parte, a través de la producción de masculinidades ejemplares (p.ej. deportistas profesionales), 
símbolos que tienen autoridad a pesar de que los hombres y niños no llegan a alcanzarlas plenamente.

Las formulaciones originales marcaron cierto énfasis en la posibilidad de cambio en las relaciones de género, en la idea de que un patrón dominante de masculinidad está abierto al cuestionamiento -de las resistencias de las mujeres al patriarcado y de los hombres como portadores de masculinidades alternativas-. La investigación ha confirmado la idea de la construcción y reconstrucción histórica de las masculinidades hegemónicas. Tanto a nivel local como al más amplio nivel social, las situaciones en las que las masculinidades fueron formadas cambian con el tiempo. Estos cambios provocaron nuevas estrategias en las relaciones de género (p.ej. el matrimonio basado en la sexoafectividad) y derivaron en redefiniciones de la masculinidad socialmente admirada (p.ej. el compañero doméstico en lugar del patriarca victoriano).

\subsection{Lo que debe desecharse}

Dos aspectos de las formulaciones tempranas sobre la masculinidad hegemónica no han resistido a las críticas y deben ser desechados. El primero es un modelo muy simple de las relaciones sociales en torno a las masculinidades hegemónicas. La formulación en Gender and Power intentó localizar todas las masculinidades ( $\mathrm{y}$ todas las feminidades) en términos de un único patrón de poder, la "dominación global" de los hombres sobre las mujeres (Connell, 1987:183). Aunque esto fue útil en su momento para prevenir que la idea de múltiples masculinidades colapsara en un abanico de estilos de vida en competición, es ahora claramente inadecuado para nuestra comprensión de las relaciones entre grupos de hombres y formas de masculinidades y de las relaciones de las mujeres con masculinidades dominantes. Por ejemplo, la dominación en las relaciones de género involucra una combinación de costos y beneficios, los desafíos a la masculinidad hegemónica emergen desde las "masculinidades de protesta" de los grupos étnicos marginalizados, y las mujeres burguesas pueden apropiarse de aspectos de la masculinidad hegemónica para construir carreras corporativas y profesionales. Claramente, se requieren mejores formas de entender la jerarquía de género.

A pesar de la crítica de la psicología del rasgo en Gender and Power, y la apelación a ideas psicoanalíticas sobre la motivación inconsciente, las enunciaciones tempranas sobre la masculinidad hegemónica, cuando intentaron caracterizar el contenido actual de diferentes configuraciones de masculinidad, a menudo recayeron en una terminología de rasgos -o no lograron ofrecer una alternativa. La noción de masculinidad como un ensamblaje de rasgos abrió el camino hacia el tratamiento de la masculinidad hegemónica como un tipo de carácter fijo que nos ha dado muchos problemas y es justamente criticado en la bibliografía psicológica reciente. No solo el concepto esencialista de la masculinidad, sino también, más generalmente, la perspectiva sobre el género como un conjunto de rasgos necesita ser trascendida completamente.

\subsection{Lo que debe ser reformulado}

A la luz de la investigación y las críticas que hemos discutido arriba, sostendremos que el concepto de masculinidad hegemónica necesita ser reformulado en cuatro áreas centrales: la naturaleza de la jerarquía de género, la geografía de las configuraciones masculinas, el proceso de encarnación social, y las dinámicas de las masculinidades. En las subsecciones siguientes ofrecemos una línea de pensamiento, y algunas sugerencias de investigación sobre cada uno de estos puntos. 


\section{3.a Jerarquía de género}

Comparada con las formulaciones originales del concepto, la investigación contemporánea ha mostrado la complejidad de las relaciones entre las diferentes construcciones de masculinidad. La investigación reciente en psicología discursiva indica cómo diferentes construcciones de masculinidad a nivel local pueden servir como alternativas tácticas. Las relaciones estructuradas entre masculinidades existen en todos los escenarios locales, la motivación hacia una versión específica de la hegemonía varía según el contexto local, y estas versiones locales inevitablemente difieren en algo una de la otra. La noción de pragmatismo dialéctico de Demetriou (2001) captura la influencia recíproca de las masculinidades entre sí; los patrones masculinos hegemónicos pueden cambiar al incorporar elementos de los otros.

Los análisis de las relaciones entre masculinidades reconocen ahora más claramente la agencia de los grupos subordinados y marginalizados -a menudo condicionados por su localización específica (como veremos más adelante). Las "masculinidades de protesta" (Poynting, Noble y Tabar, 2003) puede ser comprendida en este sentido: un patrón de masculinidad construido en escenarios locales de clases trabajadoras, a veces entre hombres marginalizados étnicamente, el cual encarna el reclamo de poder típico de las masculinidades hegemónicas regionales en los países occidentales, pero carece de los recursos económicos y la autoridad institucional que sustenta los patrones regionales y globales.

Las investigaciones han documentado también la durabilidad o pervivencia de los patrones no hegemónicos de masculinidad, que pueden representar respuestas bien elaboradas a la marginación étnico racial, la discapacidad física, la inequidad de clase, o la estigmatización sexual. La hegemonía puede ser alcanzada a través de su incorporación en un orden de género en funcionamiento, más que por la opresión activa en forma de descrédito o violencia. En la práctica, tanto la incorporación como la opresión pueden ocurrir juntas. Es decir, por ejemplo, la posición contemporánea de las masculinidades gais en los centros urbanos occidentales, donde las comunidades gais tienen un espectro de experiencias que van desde la violencia homofóbica y la denigración cultural hasta la tolerancia e incluso la celebración cultural y la representación política. Procesos similares de incorporación y opresión pueden ocurrir entre chicas y mujeres que construyen masculinidades (Messerschmidt, 2004).

El concepto de masculinidad hegemónica fue originalmente formulado en tándem con el concepto feminidad hegemónica -rápidamente renombrado "feminidad enfatizada"- para reconocer la posición asimétrica de las masculinidades y las feminidades en un orden de género patriarcal. En el desarrollo de las investigaciones sobre hombres y masculinidades esta relación salió del foco. Esto es lamentable por más de una razón, el género es siempre relacional, y los patrones de masculinidad son socialmente definidos en oposición a algún modelo (sea real o imaginado) de feminidad.

Tal vez sea más importante señalar que hacer foco sólo en las actividades de los hombres obtura las prácticas de las mujeres en la construcción del género entre hombres. Como bien muestran las investigaciones sobre historias de vida, las mujeres son centrales en muchos de los procesos de construcción de las masculinidades -como madres; como compañeras de aula; como novias, parejas sexuales y esposas; como trabajadoras en la división sexual del trabajo, etc.-. El concepto de "feminidad enfatizada" se enfocaba en la conformidad con el patriarcado, y esto sigue siendo de gran relevancia en la cultura de masas contemporánea. De todas formas, las jerarquías de género también pueden ser afectadas por nuevas configuraciones de las identidades de las prácticas de las mujeres, especialmente entre las más jóvenes -configuraciones que están siendo crecientemente reconocidas por los hombres jóvenes. Consideramos que las investigaciones sobre masculinidad hegemónica ahora necesitan poner más atención a las prácticas de las mujeres y a la interacción histórica entre feminidades y masculinidades. 
Sugerimos, por lo tanto, que nuestra comprensión de la masculinidad hegemónica necesita incorporar una visión más holística de la jerarquía de género, reconociendo la agencia de los grupos subordinados tanto como el poder de los grupos dominantes y el mutuo condicionamiento de las dinámicas de género y otras dinámicas sociales. Pensamos que esto tenderá, con el tiempo, a reducir el aislamiento de los estudios sobre hombres y enfatizará la relevancia de la dinámica de género en los problemas que están siendo explorados en otros campos de las ciencias sociales desde los efectos de la globalización hasta los asuntos sobre violencia y pacificación.

\section{3.b La jerarquía de las masculinidades}

El cambio en las construcciones locales de la masculinidad hegemónica han sido un tema de investigación en las últimas dos décadas. Pero con la creciente atención hacia la globalización, también se ha señalado la importancia de las arenas transnacionales para la construcción de la masculinidad. Hooper $(1998,2000)$ describe el desarrollo de la masculinidad hegemónica y otras masculinidades en las arenas de las relaciones internacionales, y Connell (1998) propuso un modelo de "masculinidad empresarial transnacional" entre los ejecutivos corporativos que está conectado con las agendas neoliberales de la globalización.

Está aún en debate si, o en qué medida, estos procesos se sobreimprimen a dinámicas de género más locales o regionales. Pease y Pringle (2001), en una reciente colección internacional, abogan por un enfoque continuo en la comprensión regional y comparativa de las masculinidades. Como mínimo debemos entender que las construcciones regionales y locales de la masculinidad hegemónica están conformadas por la articulación de estos sistemas de género con procesos globales. En este sentido, Kimmel (2005) ha examinado recientemente cómo los efectos de una masculinidad hegemónica global están incorporados en el surgimiento de "masculinidades de protesta" regionales (supremacistas blancos en Estados Unidos y Suecia) y globales (Al Qaeda en Oriente Medio).

Consideramos que estos asuntos son ahora inevitables para los estudios de la masculinidad y sugerimos el siguiente marco. Las masculinidades hegemónicas empíricamente existentes pueden ser analizadas en tres niveles:

1. Local: construidas en la interacción cara a cara de familias, organizaciones y comunidades cercanas, como podemos encontrar típicamente en la etnografía y en la investigación de historias de vida.

2. Regional: construidas a nivel de la cultura o del Estado-Nación, como podemos encontrar típicamente en la investigación discursiva política y demográfica.

3. Global: construidas en las arenas transnacionales, como la política mundial, los negocios y los medios de comunicación transnacionales, como se estudia en la investigación emergente sobre masculinidades y globalización.

Los vínculos entre estos niveles no sólo existen, sino que pueden ser importantes en la política de género. Las instituciones globales presionan los órdenes de género locales y regionales; mientras estos últimos proveen materiales culturales adaptados o reelaborados en arenas globales, y proveen modelos de masculinidad que pueden ser importantes en las dinámicas locales de género.

Consideremos específicamente la relación entre las masculinidades regionales y locales. La masculinidad hegemónica a nivel regional es simbólicamente representada a través de la 
interrelación entre prácticas masculinas locales y específicas, que tienen significado regional, como las construidas por actores de películas, atletas profesionales y políticos. El contenido específico de estas prácticas varía con el tiempo y en las distintas sociedades. Sin embargo, la masculinidad hegemónica regional da forma a un sentido social de la realidad masculina y, por lo tanto, opera en el dominio cultural como un recurso a mano a ser actualizado, alterado o cuestionado a través de la práctica en un rango de distintas circunstancias locales. Una masculinidad hegemónica regional, entonces, provee un marco cultural que puede ser materializado en prácticas e interacciones cotidianas.

Como ilustración de esta interacción entre la masculinidad hegemónica regional y local, consideremos el ejemplo del deporte. En las sociedades occidentales, la práctica a nivel local -tal como participar en eventos deportivos profesionales- construye modelos masculinos hegemónicos (p.ej. "estrellas deportivas") a nivel regional, que a su vez afectan otros escenarios locales. La investigación sobre escuelas secundarias provee un ejemplo paradigmático, al indicar que la participación exitosa en el deporte es, a menudo, una práctica masculina hegemónica destacada en este escenario local particular (Messner, 2002). Por ejemplo, Light y Kirk (2000) examinan una escuela secundaria australiana de élite, y encuentran que existe una clara estructura de masculinidades en esta escuela, en la cual una forma hegemónica específica ha sido moldeada a través de la práctica encarnada del rugby -un código que, por supuesto, no se limita a esta escuelacentrándose en la dominación, agresión, competencia despiadada y la entrega total por la escuela (Cf. Burgess, Edwards y Skinner, 2003). Entonces, los modelos masculinos ejemplares regionalmente significativos influencian -aunque no determinan completamente- la construcción de relaciones de género y masculinidades hegemónicas en el nivel local.

Es tentador asumir una simple jerarquía de poder o autoridad, que vaya desde lo global hacia lo regional y lo local, pero esto podría ser engañoso. En las discusiones sobre globalización, la determinación del poder de lo global es frecuentemente sobreestimada, mientras que la resistencia y la capacidad de lo que llamamos regional es poco reconocida (Mittelman, 2004). La escasa investigación llevada a cabo hasta ahora sobre masculinidades en la arena global (p.ej. Connell y Wood, 2005; Hooper, 2001) no sugiere que se trate de una formación poderosa con la capacidad de imponerse a las masculinidades regionales o locales. Si bien la evidencia sobre las dinámicas globales de género está en expansión, y está claro que procesos tales como la reestructuración económica, la migración de larga distancia, y la turbulencia de las agendas de "desarrollo" tienen poder para redefinir los patrones locales de masculinidad y feminidad (Connell, 2005; Morrell y Swart, 2005). Hay muchas razones para pensar que las interacciones entre las masculinidades a nivel global van a volverse más importantes en la política de género, y esta es un área clave para futuras investigaciones sobre hegemonía.

Adoptar un marco analítico que distinga entre masculinidades locales, regionales y globales (y lo mismo aplica para las feminidades) nos permite reconocer la importancia del lugar sin caer en un mundo monádico de culturas o discursos totalmente independientes. Arroja también algo de luz sobre el problema de las múltiples masculinidades hegemónicas mencionado más arriba. Aunque los modelos de masculinidad hegemónica pueden diferir unos de otros, generalmente se superponen. La interacción con las dinámicas de género a nivel social es parte de la explicación. Es más, las masculinidades hegemónicas son, como acabamos de sostener, constituidas en gran medida en interacción con las mujeres; por lo tanto, los puntos en común con las prácticas de género de las mujeres también producen convergencia. Por consiguiente, las construcciones locales de masculinidad hegemónica tienen cierto "parecido de familia", para usar el término de Wittgenstein, más que una identidad lógica. En este sentido, la pluralidad local es compatible con la singularidad de la masculinidad hegemónica a nivel regional o social. El "parecido de familia" entre variantes locales suele ser representado por un modelo simbólico a nivel regional, no por múltiples modelos. 


\section{3.c Encarnación social}

En las primeras formulaciones del concepto se ha reconocido que la masculinidad hegemónica está relacionada con las formas particulares en las que se representa y usa el cuerpo de los hombres. Sin embargo, el patrón de encarnación involucrado en la hegemonía no ha sido teorizado convincentemente.

La importancia de la encarnación masculina para la identidad y el comportamiento emerge en diversos contextos. En la juventud, la destreza corporal deviene un indicador primario de masculinidad, como ya hemos visto con el deporte. Esta es una forma clave en la que la heterosexualidad y la masculinidad se vinculan en la cultura occidental, con el prestigio conferido a los varones con parejas heterosexuales y al aprendizaje sexual imaginado como exploración y conquista. Las prácticas como comer carne y correr riesgos en las carreteras también se vinculan con las identidades masculinas. Esto lógicamente resulta en estrategias de promoción de la salud que funcionan a través de la desgenerización -el cuestionamiento de la masculinidad hegemónica o moviendo a los hombres hacia posiciones más andróginas. Pero las dificultades de las estrategias de desgenerización están también parcialmente basadas en la encarnación, por ejemplo, en el involucramiento en prácticas de riesgo como forma de establecer una reputación masculina en el contexto del grupo de pares.

La interpretación común de las ciencias sociales sobre los cuerpos como objetos de un proceso de construcción social es ahora ampliamente considerada como inadecuada. Los cuerpos están involucrados más activamente, más íntimamente y más intrincadamente en los procesos sociales que lo concebido por la teoría social. Los cuerpos participan en la acción social delineando cursos de conducta -el cuerpo es partícipe en la generación de prácticas sociales-. Es importante no sólo que las masculinidades sean comprendidas en su carácter de encarnadas, sino también abordar el entramado de la encarnación y el contexto social.

La necesidad de un tratamiento más sofisticado de la encarnación en la masculinidad hegemónica se hace evidente por la cuestión de las prácticas transgénero, que son difíciles de comprender en un modelo simple de construcción social. Este asunto ha sido reconceptualizado por el crecimiento de la teoría queer, la cual ha tratado las transiciones de género como una subversión del orden de género, o al menos como una demostración de su vulnerabilidad. Han surgido agudos debates sobre el transexualismo, donde algunos psiquiatras cuestionan la mera posibilidad del cambio de género. Por ello, no es fácil confiarse sobre las implicaciones de la práctica transgenero para la hegemonía. Siguiendo a Rubin (2003) y Namaste (2000), consideramos que las masculinidades trans no son inherentemente contrahegemónicas. Los "hombres que se hacen a sí mismos" pueden buscar la igualdad de género u oponerse a ella, tal como pueden hacerlo los hombres cis. Lo que subraya la experiencia trans es la concepción moderna del cuerpo como el "medio a través del cual las personas interactúan entre sí" (Rubin, 2003:180).

Para comprender la encarnación y la hegemonía, necesitamos entender que los cuerpos son al mismo tiempo objetos y agentes de la práctica social (Connell, 2002). Hay circuitos de práctica social que vinculan los procesos corporales y las estructuras sociales -muchos de ellos se suman a los procesos históricos en los que la sociedad es encarnada. Estos circuitos de encarnación social pueden ser muy directos y simples, o largos y complejos, pasando a través de instituciones, relaciones económicas, símbolos culturales, etc. -sin dejar de involucrar a los cuerpos materiales-. Esto puede ilustrarse fácilmente pensando en los patrones de género en la salud, la enfermedad y el tratamiento médico. 
Entre los grupos dominantes de hombres, los circuitos de encarnación social involucran constantemente las instituciones sobre las que se apoyan sus privilegios. Esto se muestra contundentemente en un estudio pionero de Donaldson y Poynting (2004) sobre la vida cotidiana de los hombres de clases dominantes. Este estudio muestra, por ejemplo, como en el deporte, el entretenimiento y las prácticas de alimentación típicas despliegan su patrimonio y establecen relaciones de distancia y dominación sobre los cuerpos de otros hombres. Se abre un rico campo de investigación, especialmente cuando consideramos cómo las costosas tecnologías -sistemas de computación, viajes aéreos globales, comunicaciones seguras- amplifican los poderes físicos de los cuerpos de los hombres de élite.

\section{3.d Las dinámicas de las masculinidades}

Aunque ha sido reconocida ampliamente, la complejidad interna de las masculinidades ha sido gradualmente puesta en foco como una cuestión vinculada a la investigación. Como sugirió nuestra discusión anterior sobre el sujeto en la práctica de género, debemos ahora reconocer explícitamente las distintas capas y la potencial contradicción interna incluidas en las prácticas que construyen las masculinidades. Estas prácticas no pueden ser leídas simplemente como la expresión de una masculinidad unitaria. Pueden, por ejemplo, representar formaciones que negocian entre deseos o emociones contradictorias, o los resultados inciertos de cálculos sobre el costo y beneficio de diferentes estrategias de género.

La investigación sobre historias de vida ha indicado otra dinámica de las masculinidades: la estructura de un proyecto. Las masculinidades son configuraciones de la práctica construidas, desplegadas, y cambiantes a lo largo del tiempo. Unos pocos estudios sobre masculinidad y envejecimiento, así como otros sobre niñez y juventud, enfatizan este asunto. El cuidadoso análisis de las historias de vida puede detectar compromisos contradictorios y transiciones institucionales que reflejan diferentes masculinidades hegemónicas y también portan semillas de cambio.

Las masculinidades hegemónicas tienden a incluir patrones específicos de división interna y conflicto emocional, precisamente a causa de su asociación con el poder generizado. Las relaciones con los padres son un probable foco de tensión, dada la división de género en el cuidado de les niñes, la cultura de las largas jornadas laborales en profesionales y gerentes, y la preocupación de los padres ricos por el manejo de su riqueza. La ambivalencia hacia los proyectos de cambio de las mujeres suele ser otro punto de tensión, que lleva a los mismos hombres a oscilar entre la aceptación y rechazo de la igualdad de género. Cualquier estrategia para mantener el poder suele involucrar una deshumanización de otros grupos y una correlativa disminución de la empatía y de la relación emocional con uno mismo (Schwalbe, 1992). Sin tratar a los hombres privilegiados con lástima, deberíamos reconocer que la masculinidad hegemónica no necesariamente se traduce en una experiencia de vida satisfactoria.

El cambio a lo largo del tiempo, aunque está forjado por contradicciones entre las masculinidades, también puede ser intencional. Tanto les niñes como les adultes tienen la capacidad de deconstruir los binarismos de género y de criticar la masculinidad hegemónica, y esta capacidad es la base de diversas intervenciones educativas y programas de cambio. Al mismo tiempo los portadores de la masculinidad hegemónica no son necesariamente "idiotas culturales"3; pueden intentar activamente modernizar las relaciones de género y reformar las masculinidades como parte de la negociación. Un buen ejemplo es la "nueva administración" en las organizaciones del sector público,

\footnotetext{
${ }^{3}$ N. de los T.: Garfinkel, en sus Estudios en etnometodología, plantea críticamente que la mirada del estructural-
} funcionalismo considera al actor como un "idiota cultural" que solo actua de acuerdo con normas que le eran impuestas. 
que rechaza la burocracia de la vieja escuela y cree en organizaciones "horizontales", la igualdad de oportunidades y políticas de empleo que contemplan las necesidades de las familias. Sin embargo, la modernización de las masculinidades no resuelve problemas, esto también, como sostiene Meuser (2001), genera contradicciones que pueden llevar a más cambios.

Las relaciones de género son siempre ámbitos de tensión. Un patrón dado de masculinidad hegemónica es hegemónico en la medida en que provee una solución a estas tensiones y tiende a estabilizar el poder patriarcal o a reconstituirlo en nuevas condiciones. Un patrón de práctica (p.ej. una versión de masculinidad) que proveyó una solución a las tensiones en las condiciones anteriores, pero no en las actuales, está abierto al cuestionamiento -de hecho, es probable que sea cuestionado-.

Este cuestionamiento ocurre continuamente, a través de los esfuerzos del movimiento de mujeres (a niveles locales, regionales y globales), entre generaciones de comunidades migrantes, entre modelos de masculinidad gerencial, entre rivales políticos, entre quienes se disputan la atención en la industria del entretenimiento, etc. El cuestionamiento es real, y la teoría de género no predice cuál prevalecerá, es un proceso abierto históricamente. Por consiguiente, la hegemonía puede fallar. El concepto de masculinidad hegemónica no se basa en una teoría de la reproducción social.

Dicho de otra manera, la conceptualización de la masculinidad hegemónica debe reconocer explícitamente la posibilidad de democratizar las relaciones de género y de abolir las asimetrías de poder, no sólo de reproducir la jerarquía. Un movimiento transicional en esta dirección requiere un intento por establecer entre los hombres una versión hegemónica -en el sentido de "hegemonía interna" de Demetriou (2002)- de la masculinidad abierta a la igualdad con las mujeres. En este sentido, es posible definir una masculinidad hegemónica completamente "positiva" -en el sentido de Collier (1998)-. La historia reciente ha mostrado la dificultad de llevar esto a la práctica. Una hegemonía positiva permanece, sin embargo, como una estrategia clave para los esfuerzos contemporáneos para la reforma.

\section{Conclusiones}

Los conceptos en las ciencias sociales surgen en respuesta a problemas intelectuales y prácticos específicos, y son formulados en lenguajes y estilos intelectuales específicos. Pero también tienen la capacidad de viajar y adquirir nuevos significados. Ciertamente esto es lo que ha sucedido con el concepto de masculinidad hegemónica, que ha sido recogido en campos que van desde la educación y la psicoterapia hasta la prevención de la violencia y las relaciones internacionales. Algunas de las ambigüedades que molestan a les crítiques provienen de los variados usos que ha encontrado el concepto y las formas en que se ha modificado en respuesta a nuevos contextos.

Este es tal vez un problema general sobre la conceptualización en las ciencias sociales y humanidades. Cuando una formulación teórica es aplicada por diferentes personas y en diferentes escenarios, el concepto debe mutar $-y$ puede hacerlo en diferentes direcciones en diferentes ámbitos-. Un concepto específico puede entonces transformarse en una "forma de decir", en un estilo de análisis, o en una figura característica en disputa. No hay nada malo en este proceso en sí mismo -es una forma habitual del desarrollo del conocimiento en las ciencias sociales-. Pero implica que los nuevos usos deben estar abiertos a la crítica y puedan perder la consistencia o la justificación de la formulación original.

Entonces, si bien recibimos la mayoría de las aplicaciones y modificaciones del concepto de masculinidad hegemónica como contribuciones a la comprensión de las dinámicas de género, rechazamos aquellos usos que implican un tipo de carácter fijo, o un ensamblaje de rasgos tóxicos. 
Estos usos no son triviales -están intentando dar nombre a asuntos significativos sobre el género, tal como la persistencia de la violencia o las consecuencias de la dominación-. Pero lo hacen de una forma que resulta conflictiva con el análisis de la hegemonía en las relaciones de género, y por tanto, no es solo una variación, sino que es incompatible tanto con la formulación inicial como con los principales desarrollos de este concepto.

Un análisis renovado de las masculinidades hegemónicas, del tipo que hemos sugerido más arriba, tiene una relevancia creciente en el momento presente de las políticas de género. En los países ricos de la metrópolis global, el cambio desde el neoliberalismo (la agenda radical de mercado formulada en los 1970s) hacia el neoconservadurismo (sumando apelaciones populistas a la religión, el etnocentrismo y la seguridad) ha hecho que las reacciones a las cuestiones de género sean un asunto política y culturalmente importante. En los países en desarrollo, los procesos de globalización han abierto los órdenes de género regionales y locales a nuevas presiones por la transformación, y también han abierto el camino a nuevas coaliciones entre grupos de hombres poderosos. En el ámbito global de las corporaciones, los medios y los sistemas de seguridad transnacionales, están siendo forjados nuevos patrones de hegemonía. La producción y el cuestionamiento de la hegemonía en órdenes de género históricamente cambiantes es un proceso de enorme importancia para el cual continuamos necesitando herramientas conceptuales. 


\section{Referencias}

Altman, D. 1972. Homosexual: Oppression and liberation. Sydney, Australia: Angus and Robertson.

Archer, L. 2001. Muslim brothers, Black lads, traditional Asians: British Muslim young men's constructions of race, religion and masculinity. Feminism \& Psychology 11 (1): 79-105.

Baca Zinn, M. 1982. Chicano men and masculinity. Journal of Ethnic Studies 10 (2): 29-44.

Barrett, F. J. 1996. The organizational construction of hegemonic masculinity: The case of the U.S. Navy. Gender, Work and Organization 3 (3): 129-42.

Belton, R. J. 1995. The beribboned bomb: The image of woman in male surrealist art. Calgary, Canada: University of Calgary Press.

Berg, L. D. 1994. Masculinity, place and a binary discourse of "theory" and "empirical investigation" in the human geography of Aotearoa/New Zealand. Gender, Place and Culture 1 (2): 245-60.

Bird, S. R. 1996. Welcome to the men's club: Homosociality and the maintenance of hegemonic masculinity. Gender \& Society 10 (2): 120-32.

Bourdieu, P. 2001. Masculine domination. Stanford, CA: Stanford University Press.

Brannon, R. 1976. The male sex role: Our culture's blueprint of manhood, and what it's done for us lately en D. S. David y R. Brannon (eds.) The forty-nine percent majority: The male sex role. Reading, MA: Addington-Wesley.

Brod, H. 1987. The making of masculinities: The new men's studies. Boston: Allen and Unwin.

---. 1994. Some thoughts on some histories of some masculinities: Jews and other others en D. S. David y R. Brannon (eds.) Theorizing masculinities. Thousand Oaks, CA: Sage.

Broker, M. 1976. "I may be a queer, but at least I am a man": Male hegemony and ascribed versus achieved gender en D. Leonard Barker y S. Allen (eds.) Sexual divisions and society. London: Tavistock.

Brown, D. 1999. Complicity and reproduction in teaching physical education. Sport, Education and Society 4 (2): 143-59.

Bufkin, J. L. 1999. Bias crime as gendered behavior. Social Justice 26 (1): 155-76.

Burgess, I., A. Edwards, and J. Skinner. 2003. Football culture in an Australian school setting: The construction of masculine identity. Sport, Education and Society 8 (2): 199-212.

Campbell, H. 2000. The glass phallus: Pub(lic) masculinity and drinking in rural New Zealand. Rural Sociology 65 (4): 562-81.

Carrigan, T., R. W. Connell, y Lee, J. 1985. Toward a new sociology of masculinity. Theory and Society 14 (5): 551-604.

Cavender, G. 1999. Detecting masculinity en J. Ferrell y N. Websdale (eds.) Making trouble: Cultural constructions of crime, deviance and control. New York: Aldine de Gruyter.

Cheng, C. 1996. "We choose not to compete": The "merit" discourse in the selection process, and Asian and Asian American men and their masculinity en C. Cheng (ed.) Masculinities in organizations. Thousand Oaks, CA: Sage.

Cockburn, C. 1983. Brothers: Male dominance and technological change. London: Pluto.

---. 1991. In the way of men: Men 's resistance to sex equality in organizations. London: Macmillan. 
Collier, R. 1998. Masculinities, crime and criminology: Men, heterosexuality and the criminal(ised) other. London: Sage.

Collinson, D. y J. Hearn. 1994. Naming men as men: Implications for work, organization and management. Gender, Work and Organization 1 (1): 2-22.

Collinson, D., D. Knights y M. Collinson. 1990. Managing to discriminate. London: Routledge.

Connell, R. W. 1977. Ruling class, ruling culture. Cambridge, UK: Cambridge University Press.

---. 1982. Class, patriarchy, and Sartre's theory of practice. Theory and Society 11:305-20.

---. 1983. Which way is up? Essays on sex, class and culture. Sydney, Australia: Allen and Unwin.

---. 1987. Gender and power. Sydney, Australia: Allen and Unwin.

---. 1990. An iron man: The body and some contradictions of hegemonic masculinity en M. Messner and D. Sabo (eds.) Sport, men and the gender order. Champaign, IL: Human Kinetics Books.

---. 1995. Masculinities. Cambridge, UK: Polity Press.

---. 1998. Masculinities and globalization. Men and Masculinities 1 (1): 3-23.

---. 2002. Gender. Cambridge, UK: Polity Press.

---. 2003. Masculinities, change and conflict in global society: Thinking about the future of men's studies. Journal of Men's Studies 11 (3): 249-66.

---. 2005. Globalization, imperialism, and masculinities en M. S. Kimmel, J. Hearn y R. W. Connell (eds.) Handbook of studies on men \& masculinities. Thousand Oaks, CA: Sage.

Connell, R. W., D. J. Ashenden, S. Kessler, y G. W. Dowsett. 1982. Making the difference: Schools, families and social division. Sydney, Australia: Allen and Unwin.

Connell, R. W. y J. Wood. 2005. Globalization and business masculinities. Men and Masculinities 1 (4): 347-64.

Consalvo, M. 2003. The monsters next door: Media constructions of boys and masculinity. Feminist Media Studies 3(1): 27-46.

Dasgupta, R. 2000. Performing masculinities? The "salaryman" at work and play. Japanese Studies 20 (2): 189-200.

Davis, A. 1983. Women, race, and class. New York: Vintage.

Demetriou, D. Z. 2001. Connell's concept of hegemonic masculinity: A critique. Theory and Society 30 (3): 337-61.

Denborough, D. 1996. Step by step: Developing respectful and effective ways of working with young men to reduce violence en C. McLean, M. Carey y C. White (eds.) Men's ways of being. Boulder, CO: Westview.

Dinges, M., E. Ründal y D. Bauer. 2004. Programm. Program for the Hegemoniale Männlichkeiten conference, Stuttgart, Germany, 24-26 June.

Donaldson, M. 1991. Time of our lives: Labor and love in the working class. Sydney, Australia: Allen and Unwin.

---. 1993. What is hegemonic masculinity? Theory and Society 22:643-57.

Donaldson, M. y S. Poynting. 2004. The time of their lives: Time, work and leisure in the daily lives of ruling-class men en N. Hollier (ed.) Ruling Australia: The power, privilege \& politics of the new ruling class. Melbourne: Australian Scholarly. 
Eisenstein, Z. R. 1979. Capitalist patriarchy and the case for socialist feminism. New York: Monthly Review Press.

Ferguson, H. 2001. Men and masculinities in late-modern Ireland en B. Pease y K. Pringle (eds.) $A$ man's world? Changing men's practices in a globalized world. London: Zed Books.

Freud, Sigmund. [1917] 1955. From the history of an infantile neurosis. Complete psychological works. Standard ed., Vol. 17. London: Hogarth.

Friedman, R. M. y L. Lerner. 1986. Toward a new psychology of men: Psychoanalytic and social perspectives. Special issue, Psychoanalytic Review 73 (4).

Gerschick, T. J. y A. S. Miller. 1994. Gender identities at the crossroads of masculinity and physical disability. Masculinities 2(1): 34-55.

Goode, W. 1982. Why men resist en B. Thorne y M. Yalom (eds.) Rethinking the family: Some feminist questions. New York: Longman.

Gutmann, M. C. 1996. The meanings of macho: Being a man in Mexico City. Berkeley: University of California Press.

Hacker, H. M. 1957. The new burdens of masculinity. Marriage and Family Living 19 (3): 227-33.

Halberstam, J. 1998. Female masculinity. Durham, NC: Duke University Press.

Hanke, R. 1992. Redesigning men: Hegemonic masculinity in transition en S. Craig (ed.) Men, masculinity, and the media. Newbury Park, CA: Sage.

Hawkesworth, M. 1997. Confounding gender. Signs: Journal of Women in Culture and Society 22 (3): 649-85.

Hearn, J. 1996. Is masculinity dead? A critique of the concept of masculinity/masculinities en M. Mac an Ghaill (ed.) Understanding masculinities: Social relations and cultural arenas. Buckingham, UK: Open University Press.

---. 2004. From hegemonic masculinity to the hegemony of men. Feminist Theory 5(1): 49-72.

Herdt, G. H. 1981. Guardians of the flutes: Idioms of masculinity. New York: McGraw-Hill.

Higate, P. R. 2003. Military masculinities: Identity and the state. London: Praeger.

Hochschild, A. 1989. The second shift: Working parents and the revolution at home. New York: Viking.

Holter, O. G. 1997. Gender, patriarchy and capitalism: A social forms analysis. Oslo, Norway: University of Oslo.

---. 2003. Can men do it? Men and gender equality? The Nordic experience. Copenhagen, Denmark: Nordic Council of Ministers.

hooks, b. 1984. Feminist theory: From margin to center. Boston: South End.

Hooper, C. 1998. Masculinist practices and gender politics: The operation of multiple masculinities in international relations en M. Zalewski y J. Parpart (eds.) The "man "question in international relations. Boulder, CO: Westview.

2000. Masculinities in transition: The case of globalization en M. H. Marchand y A. S. Runyan (eds.) Gender and global restructuring. London: Routledge.

---. 2001. Manly states: Masculinities, international relations, and gender politics. New York: Columbia University Press. 
Hunt, P. 1980. Gender and class consciousness. London: Macmillan.

Ishii-Kuntz, M. 2003. Balancing fatherhood and work: Emergence of diverse masculinities in contemporary Japan en J. E. Roberson y N. Suzuki (eds.) Men and masculinities in contemporary Japan. London: Routledge Curzon.

Jansen, S. C. y D. Sabo. 1994. The sport-war metaphor: Hegemonic masculinity, the Persian-Gulf war, and the new world order. Sociology of Sport Journal 11 (1): 1-17.

Jefferson, T. 1994. Theorizing masculine subjectivity en T. Newburn y E. A. Stanko (eds.) Just boys doing business? Men, masculinities and crime. London: Routledge.

---. 2002. Subordinating hegemonic masculinity. Theoretical Criminology 6(1): 63-88.

Kessler, S. J., D. J. Ashenden, R. W. Connell, y G. W. Dowsett. 1982. Ockers and disco-maniacs. Sydney, Australia: Inner City Education Center.

Kimmel, M. S. 1987. Rethinking "masculinity": New directions in research en M. S. Kimmel (ed.) Changing men: New directions in research on men and masculinity. Newbury Park, CA: Sage.

---. 2005. Globalization and its mal(e)contents: The gendered moral and political economy of terrorism en M. S. Kimmel, J. Hearn, and R. W. Connell (eds.) Handbook of studies on men \& masculinities. Thousand Oaks, CA: Sage.

Kimmel, M. S. y M. Mahler. 2003. Adolescent masculinity, homophobia, and violence: Random school shootings, 1982-2001. American Behavioral Scientist 46 (10): 1439-58.

Kupers, T. A. 1993. Revisioning men's lives: Gender, intimacy, and power. New York: Guilford.

Lea, S., y T. Auburn. 2001. The social construction of rape in the talk of a convicted rapist. Feminism \& Psychology 11 (1): 11-33.

Light, R., y D. Kirk. 2000. High school rugby, the body and the reproduction of hegemonic masculinity. Sport, Education and Society 5 (2): 163-76.

Mac an Ghaill, M. 1994. The making of men: Masculinities, sexualities and schooling. Buckingham, UK: Open University Press.

Maclnnes, J. 1998. The end of masculinity: The confusion of sexual genesis and sexual difference in modern society. Buckingham, UK: Open University Press.

Martin, P. Y. 1998. Why can't a man be more like a woman? Reflections on Connell's masculinities. Gender \& Society 12 (4): 472-74.

---. 2001. "Mobilizing masculinities": Women's experiences of men at work. Organizations 8 (4): 587618.

Martino, W. 1995. Boys and literacy: Exploring the construction of hegemonic masculinities and the formation of literate capacities for boys in the English classroom. English in Australia 112:11 -24.

McMahon, A. 1993. Male readings of feminist theory: The psychologization of sexual politics in the masculinity literature. Theory and Society 22 (5): 675-95.

Messerschmidt, J. W. 1993. Masculinities and crime: Critique and reconceptualization of theory. Lanham, MD: Rowman \& Littlefield.

---. 1995. Managing to kill: Masculinities and the space shuttle Challenger explosion. Masculinities 3(4): 1-22.

--- 1997. Crime as structured action: Gender, race, class and crime in the making. Thousand Oaks, CA: Sage. 
---. 2000. Nine lives: Adolescent masculinities, the body, and violence. Boulder, CO: Westview.

---. 2004. Flesh \& blood: Adolescent gender diversity and violence. Lanham, MD: Rowman \& Littlefield.

---. 2005. Men, masculinities, and crime en M. S. Kimmel, J. Hearn, and R. W Connell (eds.) Handbook of studies on men \& masculinities. Thousand Oaks, CA: Sage.

Messner, M. A. 1992. Power at play: Sports and the problem of masculinity. Boston: Beacon.

---. 1997. Politics of masculinities: Men in movements. Thousand Oaks, CA: Sage.

---. 2002. Taking the field: Women, men, and sport. Minneapolis: University of Minnesota Press.

Messner, M. A. y D. Sabo (eds). 1990. Sport, men, and the gender order: Critical feminist perspectives. Champaign, IL: Human Kinetics Books.

Meuser, M. 2001. "This doesn't really mean she's holding a whip": Transformation of the gender order and the contradictory modernization of masculinity. Diskurs 1:44-50.

---. 2003. Modernized masculinities? Continuities, challenges and changes in men's lives en S. Ervo and T. Johannson (eds.) Among men: Moulding masculinities. Aldershot, UK: Ashgate.

Meuser, M., y C. Behnke. 1998. Tausendundeine Männlichkeit? Männlichkeitsmuster und socialstrukturelle Einbindungen. Widersprüche 67:7-25.

Mieli, M. 1980. Homosexuality and liberation: Elements of a gay critique, translated by D. Fernbach. London: Gay Men's Press.

Mittelman, J. H. 2004. Whither globalization? The vortex of knowledge and ideology. London: Routledge.

Morin, S. E. y E. M. Garfinkle. 1978. Male homophobia. Journal of Social Issues 34 (1): 29-47.

Morrell, R. 1998. Of boys and men: Masculinity and gender in southern African studies. Journal of Southern African Studies 24 (4): 605-30.

Morrell, R. y S. Swart. 2005. Men in the Third World: Postcolonial perspectives on masculinity en M.

S. Kimmel, J. Hearn, and R. W. Connell (eds.) Handbook of studies on men \& masculinities. Thousand Oaks, CA: Sage.

Morris, C. y N. Evans. 2001. "Cheese makers are always women": Gendered representations of farm life in the agricultural press. Gender, Place and Culture 8 (4): 375-90.

Mosher, D. L., y S. S. Tomkins. 1988. Scripting the macho man: Hypermasculine socialization and enculturation. Journal of Sex Research 25 (1): 60-84.

Namaste, V. K. 2000. Invisible lives: The erasure of transsexual and transgendered people. Chicago: University of Chicago Press.

Newburn, T. y E. A. Stanko. 1994. Just boys doing business? Men, masculinities, and crime. New York: Routledge.

Pease, B. y K. Pringle (eds). 2001. A man's world? Changing men's practices in a globalized world. London: Zed Books.

Petersen, A. 1998. Unmasking the masculine: "Men " and "identity" in a sceptical age. London: Sage. ---. 2003. Research on men and masculinities: Some implications of recent theory for future work. Men and Masculinities 6 (1): 54-69.

Pleck, J. 1981. The myth of masculinity. Cambridge, MA: MIT Press. 
Plummer, K. (ed.). 1981. The making of the modern homosexual. London: Macmillan.

Poynting, S., G. Noble y P. Tabar. 2003. "Intersections" of masculinity and ethnicity: A study of male Lebanese immigrant youth in Western Sydney. Unpublished manuscript, University of Western Sydney.

Roberts, P. 1993. Social control and the censure(s) of sex. Crime, Law and Social Change 19(2): 17186.

Roper, M. 1994. Masculinity and the British organization man since 1945. Oxford, UK: Oxford University Press.

Rubin, H. 2003. Self-made men: Identity and embodiment among transsexual men. Nashville, TN: Vanderbilt University Press.

Sabo, D. y D. F. Gordon (eds.). 1995. Men's health and illness: Gender, power and the body. Thousand Oaks, CA: Sage.

Sabo, D. y S.C. Jansen. 1992. Images of men in sport media: The social reproduction of gender order en S. Craig (ed.) Men, masculinity, and the media. Newbury Park, CA: Sage.

Salisbury, J. y D. Jackson. 1996. Challenging macho values: Practical ways of working with adolescent boys. Washington, DC: Falmer.

Schwalbe, M. 1992. Male supremacy and the narrowing of the moral self. Berkeley Journal of Sociology 37:29-54.

Scott, J. W. 1997. Comment on Hawkesworth's "confounding gender." Signs: Journal of Women in Culture and Society 22 (3): 697-702.

Segal, L. 1990. Slow motion: Changing masculinities, changing men. London: Virago.

Skelton, A. 1993. On becoming a male physical education teacher: The informal culture of students and the construction of hegemonic masculinity. Gender and Education 5 (3): 289-303.

Snodgrass, J. (ed.). 1977. For men against sexism: A book of readings. Albion, CA: Times Change Press.

Stoller, R. J. 1968. Sex and gender: On the development of masculinity and femininity. New York: Science House.

Taga, F. 2003. Rethinking male socialization: Life histories of Japanese male youth en K. Louie y M. Low (eds.) Asian masculinities. London: Routledge Curzon.

Thorne, B. 1993. Gender play. New Brunswick, NJ: Rutgers University Press.

Thornton, M. 1989. Hegemonic masculinity and the academy. International Journal of the Sociology of Law 17:115-30.

Toison, A. 1977. The limits of masculinity. London: Tavistock.

Tomsen, S. 2002. Hatred, murder and male honour: Anti-homosexual homicides in New South Wales, 1980-2000. Vol. 43. Canberra: Australian Institute of Criminology.

Valdés, T. y J. Olavarría. 1998. Ser hombre en Santiago de Chile: A pesar de todo, un mismo modelo en T. Valdés y J. Olavarría (eds.) Masculinidades y equidad de género en América Latina. Santiago, Chile: FLACSO/UNFPA.

Wajcman, J. 1999. Managing like a man: Women and men in corporate management. Sydney, Australia: Allen and Unwin.

Walby, S. 1997. Gender transformations. London: Routledge. 
Warren, S. 1997. Who do these boys think they are? An investigation into the construction of masculinities in a primary classroom. International Journal of Inclusive Education 1 (2): 207-22.

Wetherell, M. y N. Edley. 1999. Negotiating hegemonic masculinity: Imaginary positions and psychodiscursive practices. Feminism and Psychology 9 (3): 335-56.

Whitehead, S.M.I 998. Hegemonic masculinity revisited. Gender, Work, and Organization 6(1): 5862.

---. 2002. Men and masculinities: Key themes and new directions. Cambridge, UK: Polity.

Willis, P. 1977. Learning to labor: How working class kids get working class jobs. Farnborough, UK: Saxon House.

Zaretsky, E. 1975. Male supremacy and the unconscious. Socialist Revolution 4:7-55 